\title{
Development and implementation of crater and flank tool wear model for hard turning simulations
}

\author{
Cristian Cappellini ${ }^{1}\left[\right.$ ] $\cdot$ Andrea Abeni $^{2}$
}

Received: 22 September 2021 / Accepted: 4 February 2022 / Published online: 18 February 2022

(c) The Author(s) 2022

\begin{abstract}
This paper concerns the tool wear in hard turning of AISI 52100 hardened steel by means of PCBN tools. The purposes of this work are the development of a tool wear model and its implementation in a FEM-based procedure for predicting crater and flank wear progression during machining operations for studying the influence of tool wear on the process in terms of tool geometry modifications and stress variation on the tool. The developed tool wear model, able to update the geometry of the worn tool as a function of the wear rate, has been implemented in the utilized Deform 2D FEM software. This new analytical model differs from the already proposed methods of existing research, since it concerns both crater and flank wear evaluation. The validation of the model has been achieved by the comparison between experimental and simulated wear parameters. For doing this, an extended experimental campaign has been accomplished. The comparison results have shown good agreement. Once validated, the FEM strategy has been utilized for examining the influence of tool wear on the effective rake angle and the related tool stresses, individuating the excessive positive rake angle value as the final tool breakage mechanism.
\end{abstract}

Keywords Hard turning · AISI 52100 steel · Tool wear modelling · Finite element simulation

\begin{tabular}{|c|c|c|c|c|}
\hline \multicolumn{3}{|c|}{ Nomenclature } & $F$ & Depth of cut exponent in extended \\
\hline$A$ & & Constant of Johnson-Cook's law & & Taylor's law \\
\hline \multirow{2}{*}{\multicolumn{2}{|c|}{$\begin{array}{l}a, b, c, d, e, f \\
B\end{array}$}} & Temperature coefficients in $B(T)$ & $f$ & Feed rate $(\mathrm{mm} / \mathrm{rev})$ \\
\hline & & Constant of Johnson-Cook's law & $F_{C}$ & Cutting force $(\mathrm{N})$ \\
\hline \multicolumn{2}{|c|}{$B(T)$} & $\begin{array}{l}\text { Temperature function of modified } \\
\text { Johnson-Cook's law }\end{array}$ & $G$ & $\begin{array}{l}\text { Tool life exponent in extended Taylor's } \\
\text { law }\end{array}$ \\
\hline \multicolumn{2}{|l|}{$C$} & Constant of Johnson-Cook's law & $H$ & Workpiece hardness (HRC) \\
\hline \multicolumn{2}{|c|}{$C_{T}$} & Constant of extended Taylor's law & $H_{0}$ & Reference hardness (HRC) \\
\hline \multicolumn{2}{|l|}{$D$} & $\begin{array}{l}\text { Hardness ratio exponent in extended } \\
\text { Taylor's law }\end{array}$ & $H_{t}$ & $\begin{array}{l}\text { Tool hardness temperature function (N/ } \\
\mathrm{mm}^{2} \text { ) }\end{array}$ \\
\hline \multicolumn{2}{|c|}{$D(\varepsilon)$} & $\begin{array}{l}\text { Hyperbolic tangent function of plastic } \\
\text { strain }\end{array}$ & $H_{w p}$ & $\begin{array}{l}\text { Workpiece hardness temperature } \\
\text { function }\left(\mathrm{N} / \mathrm{mm}^{2}\right)\end{array}$ \\
\hline \multicolumn{2}{|l|}{$d_{C}$} & Depth of cut (mm) & $J(H R C)$ & Hardness function in modified Johnson- \\
\hline \multirow[t]{3}{*}{$E$} & & Feed rate exponent in extended Taylor's & & Cook's law \\
\hline & & law & $k$ & Material shear stress (MPa) \\
\hline & & & $K(H R C)$ & $\begin{array}{l}\text { Hardness function in modified Johnson- } \\
\text { Cook's law }\end{array}$ \\
\hline \multirow{4}{*}{$\Delta$} & \multirow{2}{*}{\multicolumn{2}{|c|}{$\begin{array}{l}\text { Cristian Cappellini } \\
\text { cristian.cappellini@unibz.it }\end{array}$}} & $K B$ & Crater wear width (mm) \\
\hline & & & $K_{H}$ & Hardness constant \\
\hline & \multirow{2}{*}{\multicolumn{2}{|c|}{$\begin{array}{l}\text { Andrea Abeni } \\
\text { andrea.abeni@unibs.it }\end{array}$}} & $K_{K T \_a b r}$ & Abrasion crater wear constant \\
\hline & & & $K_{K T \_d i f f}$ & Diffusion crater wear constant \\
\hline \multirow[t]{2}{*}{1} & \multirow{2}{*}{\multicolumn{2}{|c|}{$\begin{array}{l}\text { Free University of Bolzano, Piazza Università } 1 \text {, } \\
\text { Bolzano 39100, Italy }\end{array}$}} & $K_{Q}$ & Diffusion activation energy constant \\
\hline & & & $K T$ & Crater wear depth $(\mu \mathrm{m})$ \\
\hline 2 & \multicolumn{2}{|c|}{ University of Brescia, Via Branze 38, Brescia 25123, Italy } & $K_{V B \_a b r}$ & Abrasion flank wear constant \\
\hline
\end{tabular}




$\begin{array}{ll}l & \text { Johnson-Cook's law strain rate exponent } \\ m & \text { Johnson-Cook's law temperature } \\ M, p, r, S & \text { exponent } \\ m_{Z} & \text { Constants of function } D(e) \\ n & \text { Friction factor in Zorev's sticking zone } \\ n_{H} & \text { Johnson-Cook's law strain exponent } \\ T & \text { Hardness exponent } \\ t & \text { Tool life (min) } \\ T_{i} & \text { Time (s) } \\ T_{i n t} & \text { Instantaneous temperature }\left({ }^{\circ} \mathrm{C}\right) \\ T_{m} & \text { Tool-chip interface temperature }\left({ }^{\circ} \mathrm{C}\right) \\ T_{r} & \text { Material melting temperature }\left({ }^{\circ} \mathrm{C}\right) \\ V B & \text { Environment temperature }\left({ }^{\circ} \mathrm{C}\right) \\ V_{C} & \text { Flank wear width }(\mu \mathrm{m}) \\ v_{S} & \text { Cutting speed }(\mathrm{m} / \mathrm{min}) \\ & \text { Tool-chip interface sliding velocity } \\ \partial W_{K T} / \partial t & \text { (mm/s) } \\ \partial W_{V B} / \partial t & \text { Crater wear rate } \\ \alpha & \text { Flank wear rate } \\ & \text { Modified Johnson-Cook's law } \\ \chi & \text { temperature coefficient } \\ \varepsilon & \text { Tool entering angle }\left({ }^{\circ}\right) \\ \dot{\varepsilon} & \text { Plastic strain }(\mathrm{mm} / \mathrm{mm}) \\ \gamma & \text { Plastic strain rate }\left(\mathrm{s}^{-1}\right) \\ \lambda & \text { Tool rake angle }\left({ }^{\circ}\right) \\ \mu & \text { Tool inclination angle }\left({ }^{\circ}\right) \\ \tau & \text { Friction coefficient in Zorev's sliding } \\ \sigma_{n} & \text { zone } \\ & \text { Tool-chip interface pressure }(\mathrm{MPa}) \\ & \text { Frictional stress }(\mathrm{MPa}) \\ & \end{array}$

\section{Introduction}

In the last years, the increasing request of high production rate, extreme flexibility and process automation, low cycle time, maintaining at the same time good quality of the manufactured part, and with a sustainable process has become a key factor for the manufacturing industry [1]. Among all the manufacturing processes, also machining operations must respect these upgrading restrictions, and due to the development of superabrasive cutting tool materials, hard turning has been rapidly developed as an affordable answer [2]. Hard turning is defined as the cutting of materials with a hardness higher than $45 \mathrm{HRC}$ [3], and it represents a profitable alternative to conventional grinding process [4]. Compared to this latter, hard turning is capable to produce better surface finish and accuracy at higher material removal rates [5]. Moreover, multiple hard turning operations can be implemented in a single setup, while this is not useful when applying conventional grinding, bringing to a reduction on process time up to $60 \%$ for hard turning [6]. Additionally, this process is usually performed in dry condition, without the application of coolants and lubricants that after need to be exhausted, enhancing the deployment of this finishing process also under a sustainability point of view [7].

Concerning the previously reported positive aspects, hard cutting process is widely spread in the industrial field. Thus, a good knowledge of its application on the quality of the final part is mandatory. To achieve this, Sankar and Rao [8] performed a sensitivity analysis of the process parameters and tool edge radius on machining forces, while turning AISI 52100 hardened steel with polycrystalline cubic boron nitride (PCBN) tools. Their findings revealed that the most affecting parameter was the tool edge radius, and the forces increase when it increases. Similarly, Pradeep et al. [9] analyzed the effects of cutting speed, feed, depth of cut, and edge radius on tool load, during the cutting of AISI 52100 steel, indicating that, while using coated carbides, not only the edge radius, but also the depth of cut heavily influence the forces. A study on the machined surface roughness has been performed by Zhang and Zhuang [10], in which AISI 52100 was processed with different chamfered carbide tools, revealing that both chamfer width and chamfer angle have influence on the surface quality. In particular, a better roughness is obtained by large chamfers with low angles. Conventional and wiper typologies of CBN tools, for turning AISI 52100 steel, have been employed by Çetinda $\breve{g}$ et al. [11] for evaluating their influence on roughness and tool wear, finding that, even the wiper tools experienced the highest tool wear, independently from the lubrication condition, the obtained surface quality was substantially better than the one achievable by conventional tools. The effects of tool geometry have been also examined in the research of Baizeau et al. [12] where the use of a honed and chamfered tool with null or negative rake angle, even if it increases the cutting forces, allows to achieve a correct displacement field in the workpiece material, avoiding undesired plowing effects and enabling the generation of appropriate shear angle. Ventura et al. [13] simulated the effects of multiple chamfer tools on the machining residual stresses in the workpiece, and on the tool wear, in orthogonal cutting of AISI 5115 steel with PCBN inserts. They concluded that by increasing the number of chamfers, the tool wear is reduced and the tool life increased, while the number of chamfers does not affect residual stresses. The importance of an optimized tool geometry, on tool life and productivity, has been also underlined by Denkena et al. [14] in the machining of different aerospace alloys with coated and uncoated carbide inserts. The tools were modified with a flank undercut that increased compression stresses on it, improving the tool life up to $75 \%$ when working titanium alloys.

In order to reduce the high production costs of PCBN tools employed in hard turning operations, the capability to forecast the tool wear, for the optimization of process parameters and of tool changing time, is mandatory [15]. 
Tool wear, in fact, influences the induced thermomechanical loading [16] and the quality of the final part, in terms of geometrical accuracy, roughness, residual stresses [17], and surface modification, that are related to the localized formation of white and dark layers [18-20]. The tool wear mechanisms in hard turning have been widely studied in the last two decades, and several related models have been developed with the purpose of predicting tool wear evolution. Poulachon et al. [21] demonstrate that at high cutting speed, when using PCBN tools to cut AISI 52100, abrasion occurs in the binder matrix, while diffusion is related to the reaction of $\mathrm{N}$ and $\mathrm{B}$ tool content with $\mathrm{FeO}$ present in the workpiece. They underlined that the higher the hardness of the binder, the lower the contribute of abrasion to tool wear. Moreover, they proposed an extended Taylor's law to evaluate the tool life as a function of materials and process parameters. Huang et al. [22] developed an analytical crater wear $(K T)$ model to calculate the volume wear losses depending on tool geometry, process parameters, and material properties. The model concerns abrasive, adhesive, and diffusive wear mechanisms. They concluded that, when using low content CBN tools (lower than $50 \%$ in weight), adhesion is negligible, and the effect of diffusive wear is reduced due to the high thermal stability of TiC binder phase. The effects of CBN content on crater wear behavior has been also analyzed by Gordon et al. [23] when machining AISI 4340 steel. They discovered that at cutting speeds over $300 \mathrm{~m} / \mathrm{min}$, the dominant wear mechanism for high content CBN is the plastic deformation of the tool, with a reduction of the abrasive-diffusive contribution and a decrease of the crater depth with high speeds. Machinability of AISI 52100 steel is also affected by flank wear $(V B)$, as stated by the study of Singh and Rao [24] where ceramic $\mathrm{Al}_{2} \mathrm{O}_{3} / \mathrm{SiC}$ tools were employed. In their work, an analytical model correlated the volume wear loss to process parameters and material characteristics, and it has been detected that adhesion and abrasion are the leading mechanisms. The relevance of these latter on flank wear, as a function of the hardness of the worked material, has been deeply investigated by Chinchanikar and Choudhury [25] indicating that when the hardness increases, the adhesive contribution reduces, and the abrasion becomes dominant.

In addition to analytical models, such as slip line field approach [26, 27], statistical techniques, and analysis of variance (ANOVA) [28] and response surface methodology (RSM) [29], other valuable tools, like artificial neural networks (ANNs) [30] and finite element (FE) simulations $[31,32]$, can be used for tool wear prediction. In particular, FE simulations have been demonstrated to be able to correctly evaluate the influencing wear parameters used in analytical models, such as tool-workpiece interface temperature, sliding velocity, and contact pressure, allowing to simulate the tool wear evolution with good accuracy
[33]. This methodology has been applied for different combinations of tool and workpiece materials [34-36], but there are poor applications in hard turning. The aim of this work is to reduce this lack of applications by developing a methodology for simulating the wear of PCBN tools in hard turning of AISI 52100 steel. A crater $(K T)$ and flank $(V B)$ tool wear model, for the evaluation of the wear rate as a function of influencing parameters, has been developed. The model has been then implemented in the utilized FE software by means of a dedicated subroutine able to move the nodes of the tool mesh for updating the geometry of the worn tool. In order to collect experimental measures of the wear parameters, several hard turning tests have been performed. The calibration and validation of the applied methodology has been achieved by the comparison of simulated results with the experimental ones. The outcomes of this comparison show good agreement between experiments and simulations, underlining the suitability of the proposed methodology for forecasting tool wear growth. Therefore, by the usage of this predictive approach, it is possible to correctly estimate the evolution of tool wear during the machining process, as a function of the employed process parameters. Thanks to this, the generation of problems and defects related to the cutting of a steel component by a worn tool, such as excessive roughness or residual stresses, and white and dark layer surface modifications, may be prevented. Moreover, the ability of forecasting the tool wear status at a specific cutting time allows to accurately design the finishing process and correctly plan tool substitution policy, leading to an excellent final product quality and to a reduction of the machining costs. Lastly, this approach enables the estimation of the stresses on the tool, bringing to the possibility of anticipating its catastrophic breakage that, again, aggravates quality and costs of the operation.

\section{Materials and methods}

In order to obtain the tool wear measurements necessary for the tailoring of the developed wear model, and tool topology update, an experimental campaign consisting of several orthogonal turning tests has been performed by the variation of the process parameters. Among these latter, different values of cutting speed $\left(V_{C}\right)$ and feed rate $(f)$ have been adopted while performing the experiments. The values of the selected cutting parameters are shown in Fig. 1, where it is possible to observe that different levels have been assigned to both cutting speed and feed rate, and the relative test name. The remaining process parameters, such as workpiece and tool material, lubrication condition, depth of cut, and geometries, have been kept constant. 


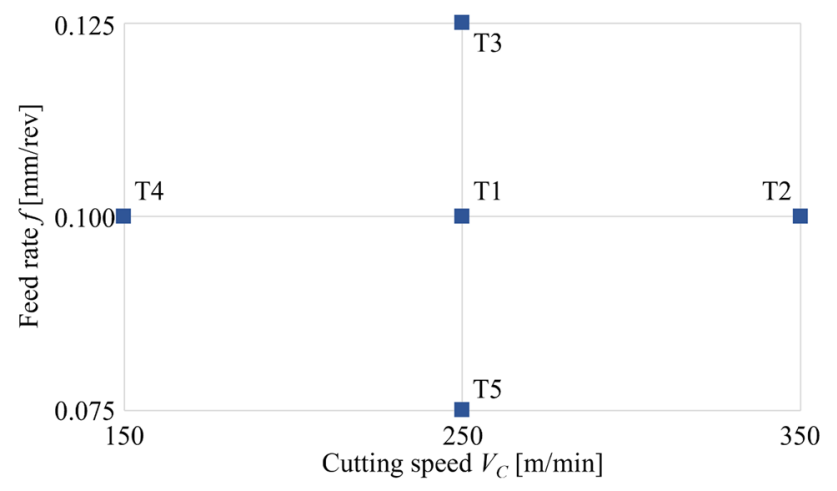

Fig. 1 Experimental cutting parameters

\subsection{Workpiece preparation}

The workpieces consisted of disks made of AISI 52100 bearing hardened steel with a thickness of $1.2 \mathrm{~mm}$ and an initial diameter of $150 \mathrm{~mm}$. AISI 52100 hardened steel material has been selected for its industrial relevance and its hardenability. The chemical composition of AISI 52100, expressed in percentage in weight, is reported in Table 1.

Before to be machined, the specimens have been prepared by means of a heat treatment cycle of quenching and tempering that is described in Fig. 2. The design and application of the heat treatment was necessary in order to obtain a disk where the material properties, in terms of mechanical behavior and hardness, were comparable with the ones usually detectable in the common industrial applications, as reported by the standard UNI EN ISO 683-17:2014 for technical characteristics of furniture of ball bearing steels.

As described in Fig. 2, the thermal cycle involved a preheating phase of normalization at $550{ }^{\circ} \mathrm{C}$ followed by a quenching treatment in which the austenitization temperature was set at $860{ }^{\circ} \mathrm{C}$. Both pre-heating and quenching treatment were performed in a salt bath. The application of this technique was mandatory in order to permit a uniform heating of the disk and consequently preventing excessive deformation of the specimen since the low thickness of the disks increases
Table 1 AISI 52100 chemical composition

\begin{tabular}{lllllllll}
\hline AISI 52,100 chemical composition & & & & & \\
\hline Element & $\mathrm{Fe}$ & $\mathrm{C}$ & $\mathrm{Cr}$ & $\mathrm{Mn}$ & $\mathrm{P}$ & $\mathrm{Si}$ & $\mathrm{S}$ \\
\hline$\%$ in weight & 97.0 & $0.980-1.10$ & 1.45 & 0.35 & $<0.025$ & 0.230 & $<0.025$ \\
\hline
\end{tabular}

the thermal distortion effect. For the same reason, instead of using oil as quenching medium, as indicated by the standard, the quenching medium was a temperature-controlled salt bath retained at $175^{\circ} \mathrm{C}$. After this phase, the cooling of the specimen at environment temperature was accomplished in air. To reduce the brittleness of the disk at this stage and to achieve the desired hardness, the specimen was then tempered in furnace at a temperature of $390{ }^{\circ} \mathrm{C}$. At the end of the tempering treatment, the disk was left to cool in air. Hardness measurements of the disk were performed at two different stages of the heat treatment cycle. The first detection was attained at the end of the air cooling after the quenching treatment, in which a range between 63 and $65 \mathrm{HRC}$ was recorded. The second one was performed at the end of the tempering treatment where a final hardness of 57 HRC was detected. Lastly, the treated disks were gently ground to obtain a flat surface of the requested thickness.

\subsection{Cutting tests and tool wear measurement}

All the orthogonal cutting tests were carried out in dry condition on a computer numerical control (CNC) lathe equipped with an induction servo motor furnishing a nominal power of $7 \mathrm{~kW}$. The exploited tool was a PCBN insert ISO TNGN 110308S-01020 CBN100 produced by Seco Tools, in which the abrasive particles of cubic-boron-nitride are dispersed in a TiC binder matrix. Chemical composition and properties of the insert are reported in Table 2. For guaranteeing a negative rake angle $(\gamma)$ of $-8^{\circ}$, an inclination angle $(\lambda)$ of $0^{\circ}$, and an entering angle $(\chi)$ of $90^{\circ}$, a toolholder ISO CTFNR3225P11PL was adopted. During the machining tests, the disks were mounted on the lathe mandrel with the aid of a specifically designed fixture, as shown in the experimental setup in Fig. 3.
Fig. 2 Heat treatment cycle applied to the specimens

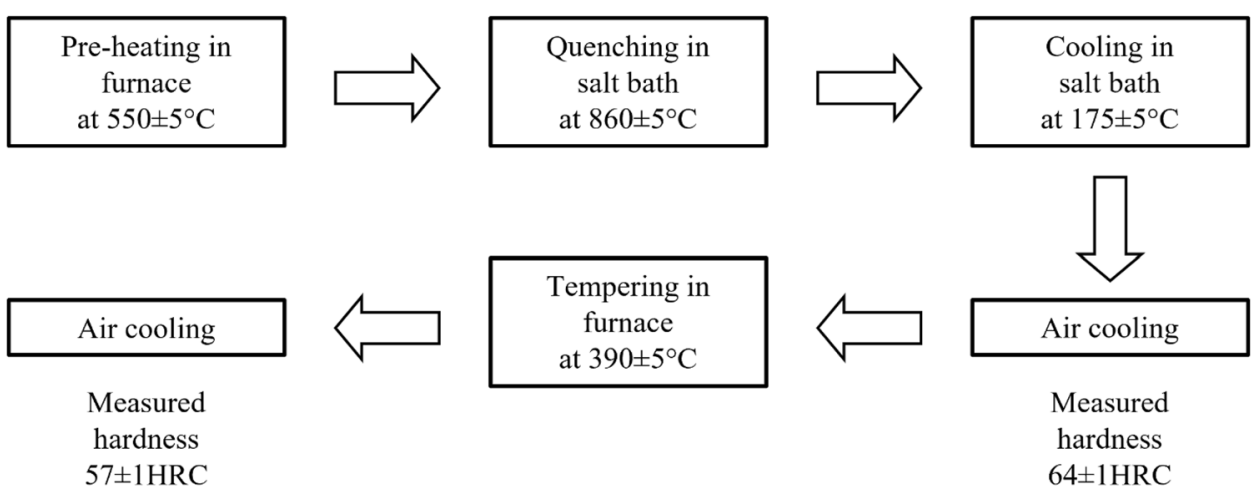


Table 2 Chemical composition and properties of the employed PCBN insert

PCBN properties (CBN 100 Seco Tools)

\begin{tabular}{lllllll}
\hline CBN content approx. vol & Binder & Knoops hardness & Young's modulus & Poisson's ratio & Thermal expansion & Thermal conductivity \\
\hline $50 \%$ & $\mathrm{TiC}$ & $27.5 \mathrm{HK}$ & $588 \mathrm{GPa}$ & 0.153 & $6.2 \times 10^{-6} 1 / \mathrm{K}$ & $40 \mathrm{~W} / \mathrm{m} \mathrm{K}$ \\
\hline
\end{tabular}

Following the tool life testing standard ISO 3685:1993, throughout each test, the tool wear parameters, in terms of flank wear $(V B)$, crater depth $(K T)$, and crater width $(K B)$, often defined as contact length, have been measured at regular time intervals. The standard reports that to determine the end of each tool life test, a total amount of the mean flank wear of $0.3 \mathrm{~mm}$, or a maximum value of flank wear of $0.6 \mathrm{~mm}$, or the catastrophic tool failure criteria have to be reached. The same criteria have been applied on the experimental tests, but it must be anticipated that, since for all the tests the tool breakage occurred before reaching the limit values of $V B$ mean or $V B$ maximum, the tool failure has been chosen as the end of each test. With the aim of determining the time intervals for each test, the estimation of the final tool life is needed. For the assessment of the tool life time, an extended Taylor's law developed by Poulachon et al. [21] has been employed. The proposed law, reported in Eq. (1), correlates the process parameters with the tool life time:

$V_{C} \cdot T^{G} \cdot f^{E} \cdot d_{C}^{F} \cdot\left(\frac{H}{H_{0}}\right)^{D}=C_{T}$ where $V_{C}$ is the cutting speed expressed in $\mathrm{m} / \mathrm{min}, T$ is the tool life expressed in minutes, $f$ is the feed rate expressed in $\mathrm{mm} / \mathrm{rev}, d_{c}$ is the depth of cut expressed in $\mathrm{mm}, H$ is the workpiece hardness expressed in HRC, and $H_{0}$ is a reference hardness equal to $60 \mathrm{HRC}$. The constant $C_{T}$ and the exponents $G, E, F$, and $D$ must be tailored as a function of workpiece and tool material. Due to the fact that these latter are analogous to those utilized in the present work, it has been possible to adopt the values already proposed in [21]. Thus, the constant $C$ was set equal to $1.72, G$ equal to 0.285 , $E$ equal to $0.335, F$ equal to 0.112 , and $D$ equal to 1.07 . The tool life values analytically calculated by Eq. (1) were found accordingly with the experimental ones; hence, Eq. (1) was applied for the estimation of the final tool life related to the cutting parameters of each test and consequently for the definition of the cutting time intervals. These latter have been obtained dividing the total tool life approximately in 10 substeps except for the test concerning a cutting speed of $150 \mathrm{~m} / \mathrm{min}$, namely test T4 showed in Fig. 1, where more than 20 substeps were used due to the longer tool life time. For measuring the tool wear, at the end of every substep,

Fig. 3 Experimental setup

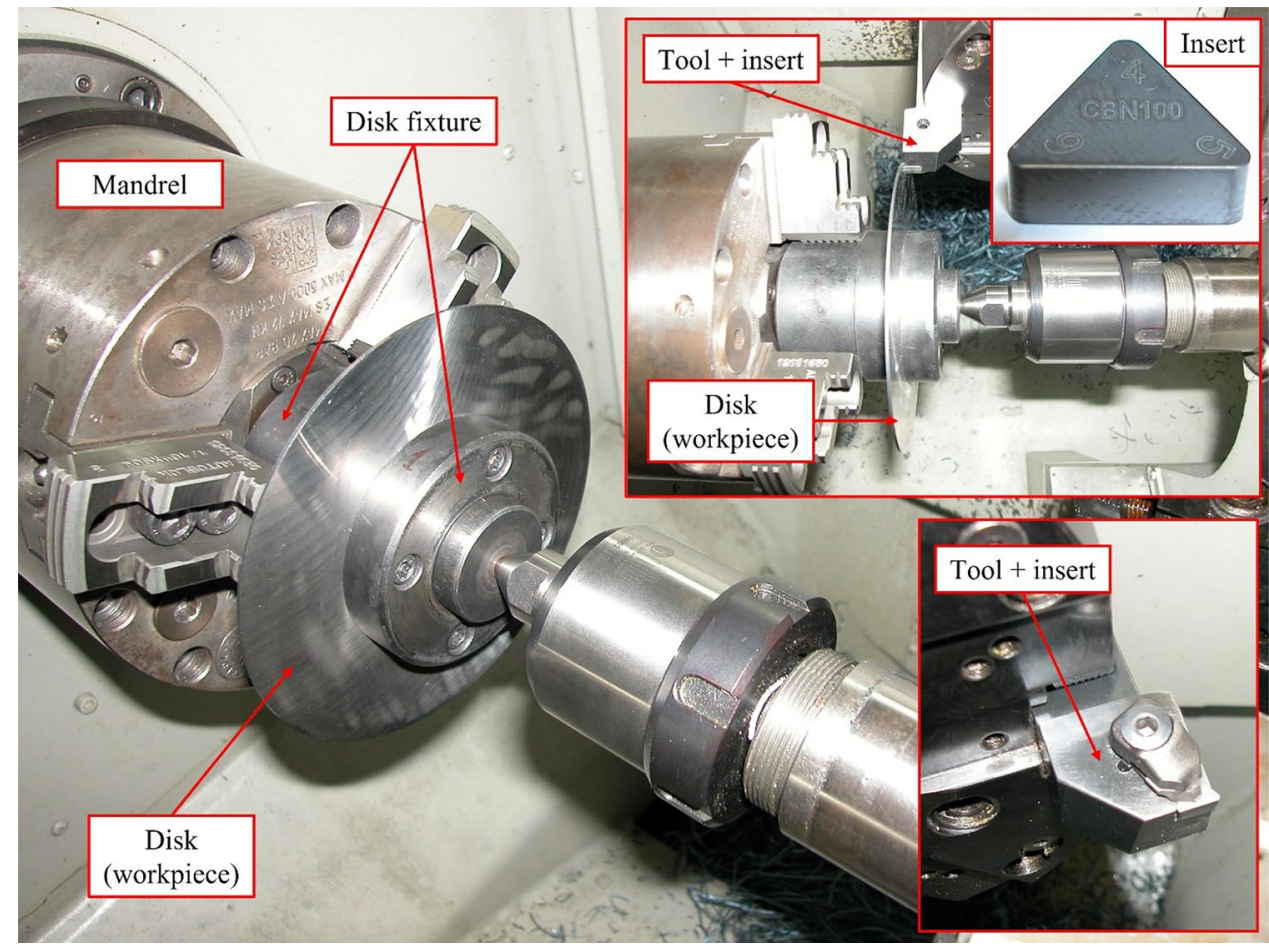




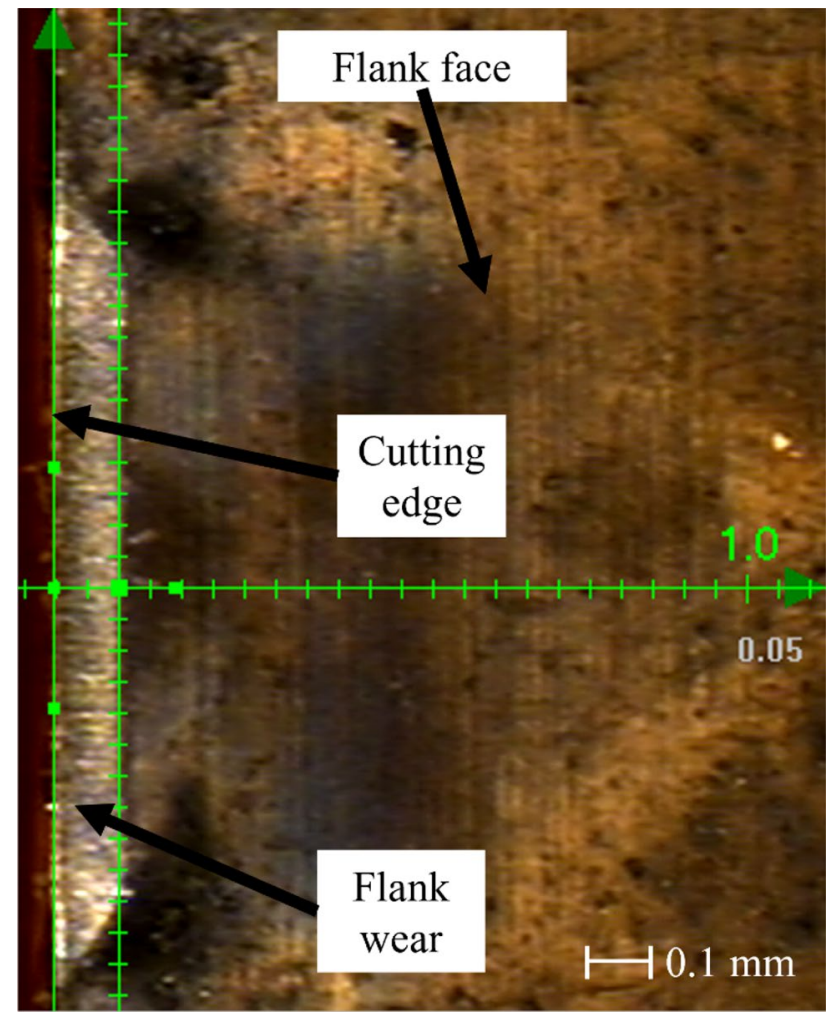

Fig. 4 Flank wear measurement procedure (test T4, cutting time $=950 \mathrm{~s}$ )

the insert was removed from the toolholder and analyzed with different equipment as a function of the wear parameter under investigation. The acquisition of both flank wear and contact length has been accomplished by means of an optical coordinate measuring machine (CMM) (Mitutoyo QS200) enabling a measuring resolution of $0.5 \mathrm{~mm}$ with an accuracy lower than $2.5 \mathrm{~mm}$. A typical flank wear measurement is visible in Fig. 4. Crater wear depth was acquired by means of a profilometer (Mitutoyo SJ-301) with a resolution of $0.01 \mathrm{~mm}$. Concerning the measurement of the crater wear depth, several profiles on the rake face area of the tool have been acquired at regular spatial intervals of $0.1 \mathrm{~mm}$. For each substep of measurement, the profilometer acquisitions were performed starting from a zone of the tool rake face that had not been in contact with the workpiece during the cutting and sliding the stylus head perpendicularly to the cutting edge. In this manner, the spatial reference of the rake face outline of the not worn area of the tool was maintained. Then, by shifting the profilometer position, of a quantity equal to the spatial interval previously defined, closer to the worn area of the tool with a direction parallel to the cutting edge, a new profile of the tool was acquired. The procedure has been then repeated up to the not worn area of the tool on the other side of the rake face. Figure 5 shows the series of acquisition of the different rake face profiles for test $\mathrm{T} 1$ at a cutting time of $150 \mathrm{~s}$. All the carried out profilometer acquisitions for each tested tool at each substep of measurement have been analyzed to individuate the value of the crater wear depth reached at that particular cutting time. As highlighted by Fig. 5, the maximum value of $K T$, among the acquired profiles, has been selected as the value of crater wear depth.

\subsection{Material constitutive model calibration}

The orthogonal cutting simulations have been performed in accordance with the experimental setup, applying the same cutting parameters and tool geometry, by means of the finite element method (FEM) software DEFORM-2D. In order to achieve reliable FE models of the cutting operation, the constitutive law of the workpiece material must be properly characterized. As reported by Melkote et al. [37], the plastic flow of the material under machining conditions is typically represented by the Johnson-Cook's (JCs) model, which general expression is described by Eq. (2), where $\varepsilon$ is the plastic strain, $\dot{\varepsilon}$ is the plastic strain rate, $T_{i}$ is the instantaneous temperature, $T_{r}$ is the environment temperature, $T_{m}$
Fig. 5 Example of the tool crater wear measurement (test $\mathrm{T} 1$, cutting time $=150 \mathrm{~s}$ )
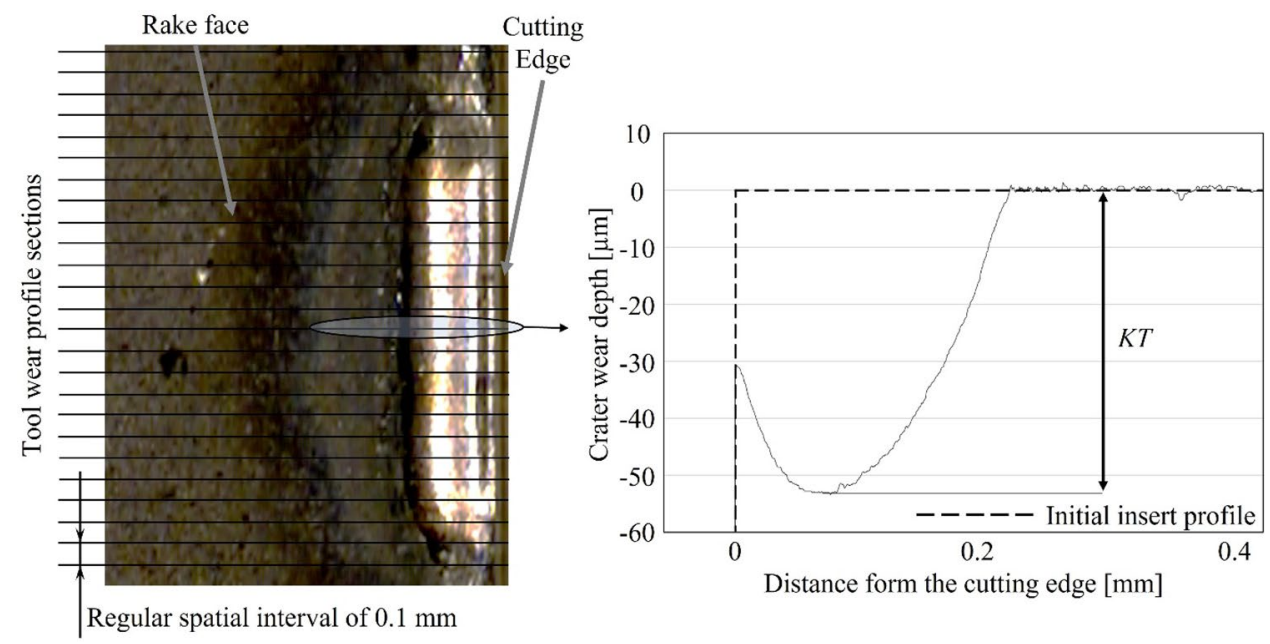
is the material melting temperature, while $A, B, C, n$, and $m$ are constants that need to be calibrated.

$\sigma=\left[A+B \varepsilon^{n}\right][1+C \ln (\dot{\varepsilon})]\left[1-\left(\frac{T_{i}-T_{r}}{T_{m}-T_{r}}\right)^{m}\right]$

Several research works, starting from this model for the characterization of the plastic behavior of AISI 52100 steel, have proposed different values of the model constants and little modifications to the general expression of the model: Huang and Liang [38] suggested a set of parameters for the prediction of machining forces; different model constants were derived by Poulachon et al. [39] in the simulation of chip morphology; Umbrello et al. [40] included a temperature-dependent hardness function to consider the generation of white and dark layer phases; Kountanya et al. [41] optimized the model for evaluating the effects of tool geometry on chip formation; while Zhang et al. [42] derived parameters for the evaluation of machining induced residual stresses. A summary of the expressions and constant values of these models is presented in Table 3.
The model representations proposed in Table 3 do not consider the material softening behavior occurring in the primary shear zone, where extreme values of temperature, strain, and strain rate are generated. In this area, hardened metals usually show shear banding phenomenon, and chip segmentation takes place [37]. In order to correctly simulate the chip segmentation, by the application of the models in Table 3 , a damage criterion must be implemented, as stated in Ceretti et al. [43]. In the present work, as reported by Arrazola et al. [44], to avoid the implementation of a damage criterion, a modification of the JC model has been proposed by multiplying it for a hyperbolic tangent function of the plastic strain. This function has the form described in Eq. (3), where $M, p$, $r$, and $S$ are parameters that need to be calibrated.

$D(\varepsilon)=M+(1+M)\left[\tanh \left(\frac{1}{(\varepsilon+p)^{r}}\right)\right]^{S}$

With the aim of determining the most accurate material model, among the ones showed in Table 3, a preliminary
Table 3 Modifications of JC model and constant values

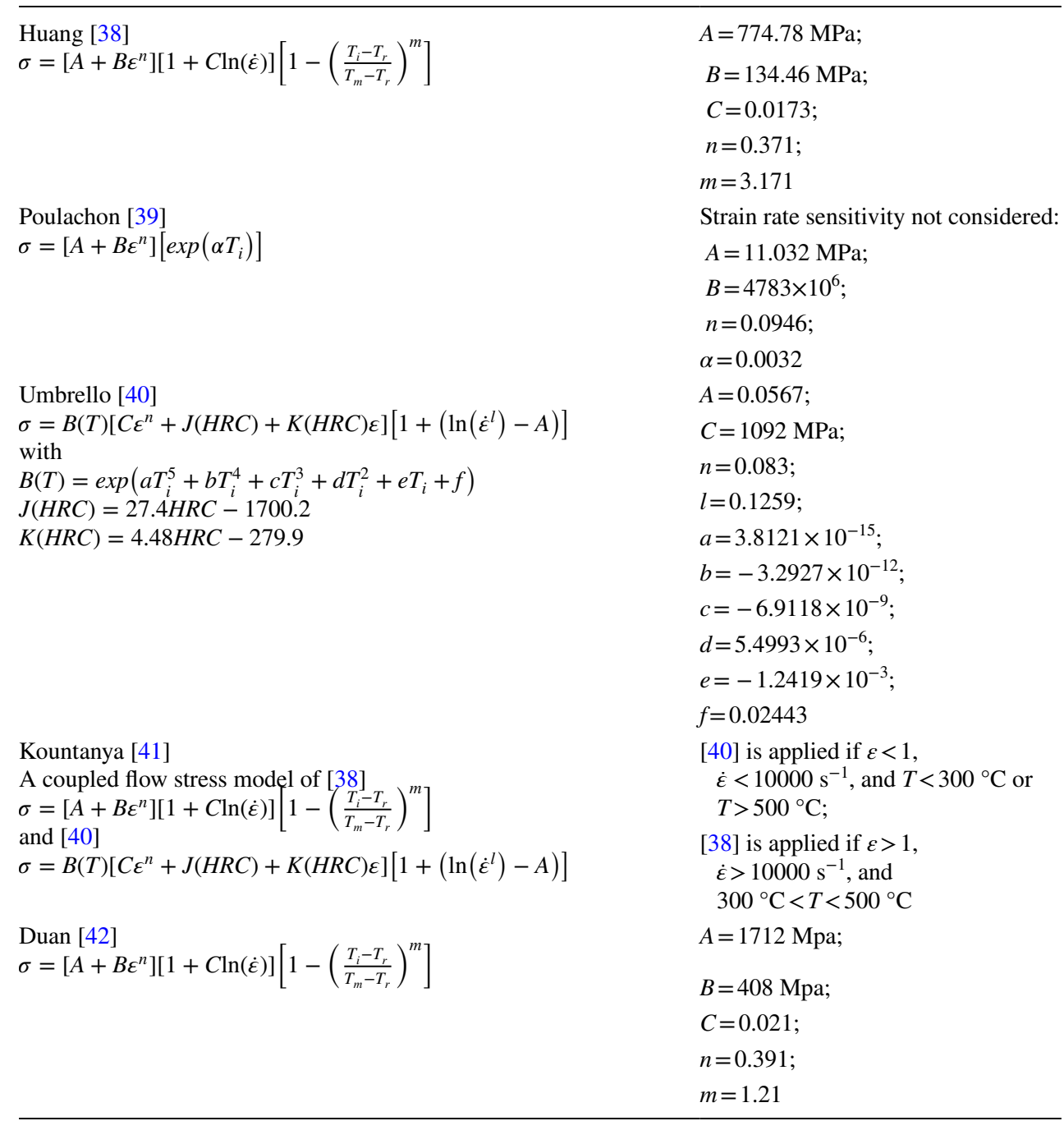


Fig. 6 Experimental and FEM simulated force comparison

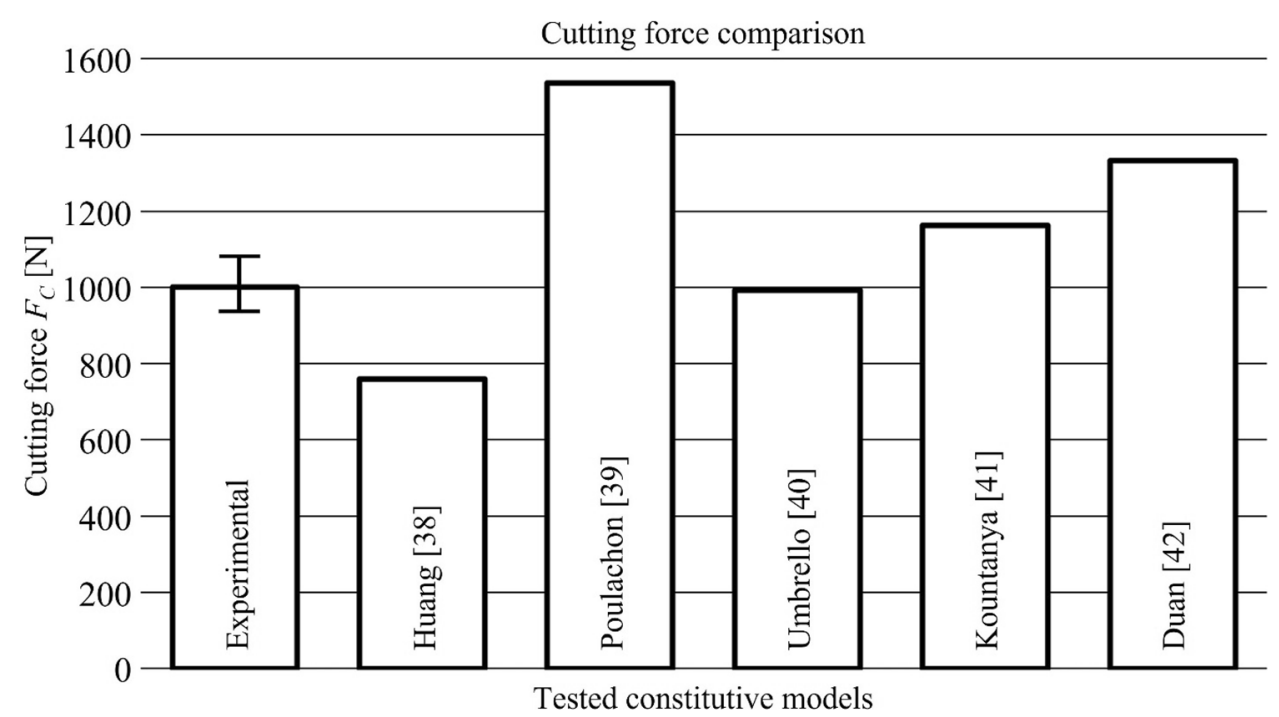

simulative campaign has been carried out implementing them into the FEM engine. For doing this, a comparison between the simulation and experimental results, in terms of cutting forces, has been performed. All the simulated material models have been modified adding the factor of Eq. (3). Due to the similarity of process conditions, the experimental evidence presented in [45] have been chosen as reference for the comparison. In particular, the simulated process parameters were a cutting speed of $75 \mathrm{~m} / \mathrm{min}$, a feed of $0.125 \mathrm{~mm} / \mathrm{rev}$, a depth of cut of $1.0 \mathrm{~mm}$, a workpiece hardness of $56.5 \mathrm{HRC}$, the same tool geometry, and tool material of the experimental setup. Workpiece and tool have been discretized with a mesh consisting of 4000 and 1000 quadrilateral elements, respectively. In particular, a highdensity mesh was defined in the tool-workpiece interface contact area both for workpiece and tool, with an average element dimension of $5 \mu \mathrm{m}$. Following the Zorev's model for friction [46], a shear friction model with a coefficient of friction $m_{Z}=1$ was applied on a contact area length of two times the uncut chip thickness from the tool edge, while a Coulomb friction model with a coefficient of $\mu=0.35$ was employed in the remaining contact length. The amount of the simulated cutting forces, and the experimental reference, are reported in Fig. 6, where it can be observed that the modified flow stress model of Umbrello [40] is able to predict the machining force with a good comparison. The other tested flow stress models underestimate [38] or overestimate $[39,41,42]$ the cutting forces.

From this comparison, the modified flow stress model of Umbrello, described by Eq. (4), has been chosen as constitutive material model for the successive tool wear simulations.

$$
\begin{gathered}
\sigma=B(T)\left[C \varepsilon^{n}+J(H R C)+K(H R C) \varepsilon\right]\left[1+\left(\ln \left(\dot{\varepsilon}^{l}\right)-A\right)\right] \\
{\left[M+(1+M)\left[\tanh \left(\frac{1}{(\varepsilon+p)^{r}}\right)\right]^{S}\right]}
\end{gathered}
$$

The calibration of the parameters of the factor $D(\varepsilon)$ of Eq. (3) has been obtained by the comparison of experimental and simulated geometry of the segmented chip. Again, the experimental chip dimensions of [45] have been taken as reference. In particular, these are an average chip valley of $48 \mu \mathrm{m}$, an average chip peak of $100 \mu \mathrm{m}$, and an average chip pitch of $70 \mu \mathrm{m}$. The parameter calibration led to the following values: $M=0.3, p=0, r=5, S=20$. Figure 7 shows the simulated segmented chip dimensions resulting from the implementation of the calibrated parameters. The values of simulated chip valley, peak, and pitch are equal to $58 \mu \mathrm{m}, 95 \mu \mathrm{m}$, and $68 \mu \mathrm{m}$ respectively. It can be noticed that there is good agreement between experimental and simulated values.

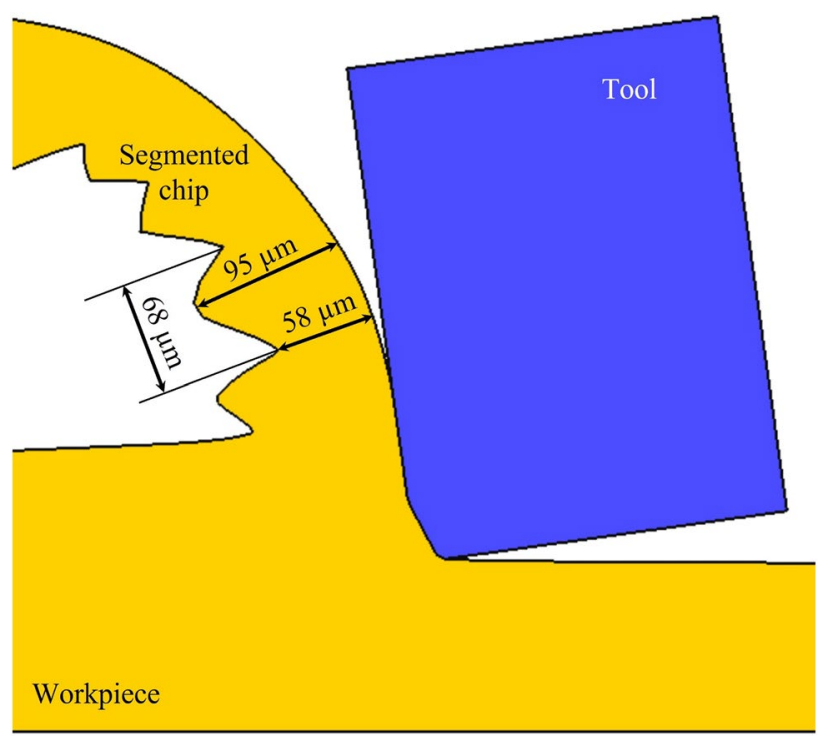

Fig. 7 Measurements of the simulated segmented chip dimensions 


\subsection{The tool wear model}

The utilization of a coupled abrasive-diffusive tool wear model is determined to consider the different wear mechanisms acting on rake and flank face of the insert. In particular, the part of the model concerning crater wear is a combination of abrasion and diffusion contribution, while, due to the high hardness of worked material, the flank wear is modelled by pure abrasion, as observed in [25]. As reported in [22], because of the relative low content of CBN, $50 \%$ in weight, with respect to higher CBN content, around $90 \%$ in weight, adhesive wear does not occur. For this reason, the adhesive contribution in the proposed model is neglected.

Following these considerations, the implemented crater wear model is a modification of the model proposed in [15], while the flank wear is evaluated by a modification of the model presented in [24]. Equation (5) reports the expression of the coupled crater-flank tool wear model implemented:

$$
\begin{cases}\frac{\partial W_{K T}}{\partial t}=K_{K T \_a b r} \cdot K_{H} \cdot\left(\frac{H_{w p}^{n_{n}-1}}{H_{t}^{n_{H}}}\right) \cdot v_{S} \cdot \sigma_{n} & \\ +K_{K T_{-} d i f f} \cdot \sqrt{v_{S}} \cdot e^{-K_{Q} /\left(T_{i n t}+273\right)} & \text { for crater wear } \\ \frac{\partial W_{V B}}{\partial t}=K_{V B_{-} a b r} \cdot K_{H} \cdot\left(\frac{H_{w p}^{n_{H}-1}}{H_{t}^{n_{H}}}\right) \cdot V_{C} \cdot \sigma_{n} & \text { for flank wear }\end{cases}
$$

where $\partial W_{K T} / \partial t$ and $\partial W_{V B} / \partial t$ are the tool wear rate for rake and flank face respectively, $H_{w p}\left[\mathrm{~N} / \mathrm{mm}^{2}\right]$ and $H_{t}[\mathrm{~N} / \mathrm{mm} 2]$ are temperature hardness functions for workpiece and tool respectively, $K_{Q}$ is a constant related to the activation energy for diffusion, $v_{S}[\mathrm{~mm} / \mathrm{s}]$ is the sliding velocity at tool-chip interface, $\sigma_{n}[\mathrm{MPa}]$ is the contact pressure at tool-chip interface, $T_{i n t}\left[{ }^{\circ} \mathrm{C}\right]$ is the temperature at tool-chip interface, $V_{C}$ $[\mathrm{mm} / \mathrm{s}]$ is the cutting speed, and $K_{H}$ and $n_{H}$ are hardness constant and hardness exponent whose values are dependent from the workpiece-tool hardness ratio. The coefficients $K_{K T_{-} a b r}, K_{K T_{-} d i f f}$, and $K_{V B_{-} a b r}$, that are related to the abrasive crater wear, the diffusive crater wear, and the abrasive flank wear respectively, have been calibrated by means of the comparison of the worn tool geometry resulting from
Table 4 Summary of the tool wear model parameter values

Values of tool wear parameters

$H_{w p}=11760 \cdot \exp \left(-16.3 \times 10^{-4} T_{i n t}\right)\left[\mathrm{N} / \mathrm{mm}^{2}\right]$

$H_{t}=45000-4.324 T_{\text {int }}\left[\mathrm{N} / \mathrm{mm}^{2}\right]$

with $T_{\text {int }}$ expressed in $\left[{ }^{\circ} \mathrm{C}\right]$

$K_{Q}=20460$

$\left\{\begin{array}{l}K_{H}=0.333 n_{H}=1.0 \quad \text { if } H_{t} / H_{w p}<0.8 \\ K_{H}=0.189 n_{H}=3.5 \text { if } 0.8<H_{t} / H_{w p}<1.25 \\ K_{H}=0.416 n_{H}=7.0 \quad \text { if } H_{t} / H_{w p}>1.25\end{array}\right.$

$K_{K T \_ \text {diff }}=24602$

$K_{V B_{-} a b r}=0.085$

the simulation with the experimental measurements of crater and flank wear of the first substep of cutting for all the performed tests. Table 4 shows the values of the tool wear model parameters and calibrated coefficients. The simulation software provides the values of contact pressure $\left(\sigma_{n}\right)$, sliding velocity $\left(v_{S}\right)$, and interface temperature $\left(T_{i n t}\right)$ in their local values. The sliding velocity for the part of the wear model related to flank has been assumed equal to the cutting speed $\left(V_{C}\right)$. By the application of the tool wear model, the amount of wear rate for each tool node in contact with the workpiece can be assessed. The developed wear model has been then implemented in the FE simulation software by a dedicated subroutine that, after the evaluation of the tool wear rate, allows the update of the worn tool geometry.

\subsection{FEM simulations}

The experimental cutting tests have been faithfully reproduced, in terms of cutting parameters, workpiece and tool material, and lubrication condition, in the FE environment. Figure 8 shows the objects of the FEM model: the tool and the workpiece at the beginning (Fig. 8a) and during the simulation where the chip formation and its segmentation are evident (Fig. 8b).

The workpiece has been considered as rigid plastic object and discretized with a mesh of more than 5000
Fig. 8 a, b Objects of the FEM model
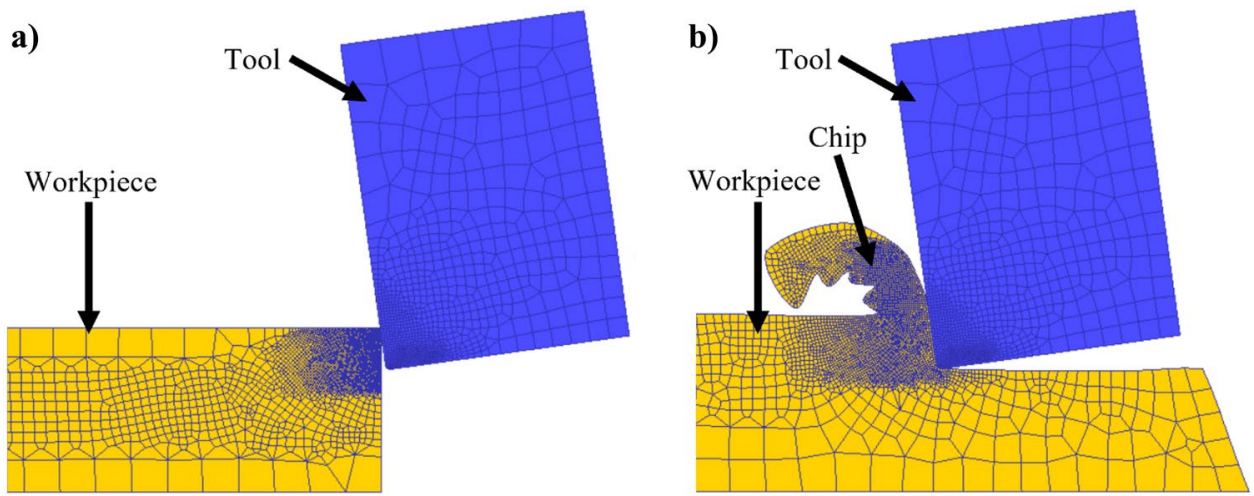
Fig. 9 Zorev's hybrid frictional model for cutting

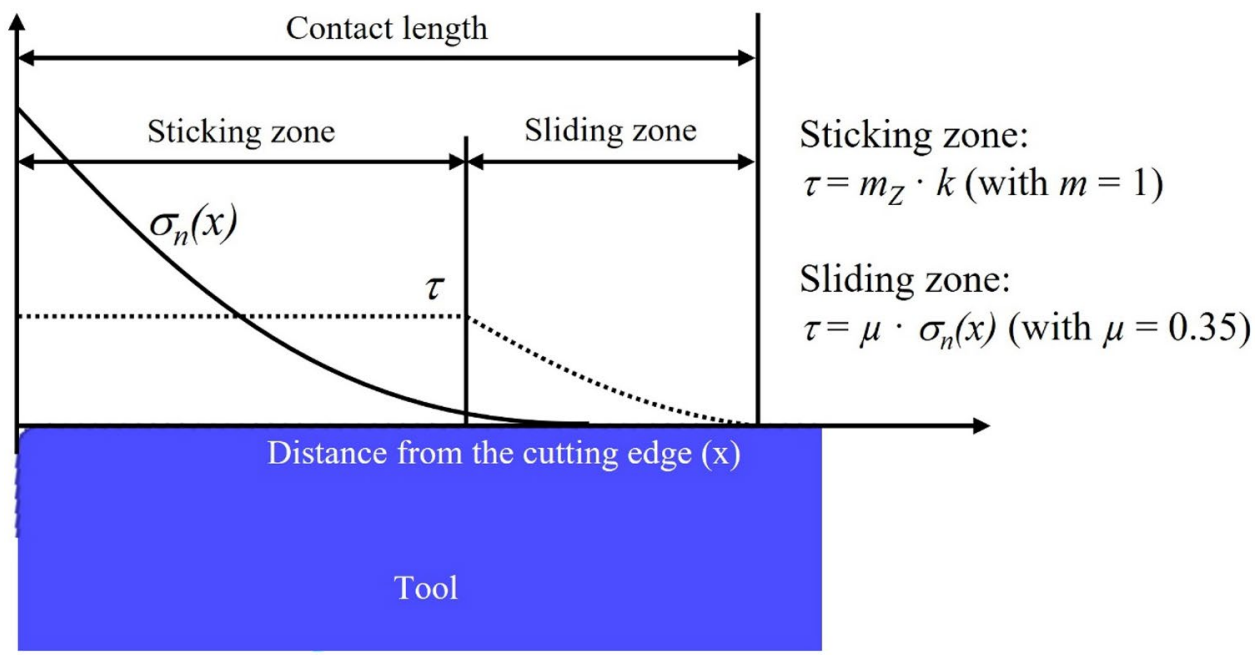

quadrilateral linear elements. The rigid plastic behavior of the workpiece material has been characterized by the modified JC model of Eq. (4). The tool has been modelled as a rigid object and meshed with more than 1000 quadrilateral linear elements. A finer mesh, in the correspondence of the tool-chip contact area, has been created, achieving a minimum element size of $0.003 \mathrm{~mm}$ for both the objects. In this manner, the generated and transferred heat between chip and tool, due to friction and plastic deformation, has been correctly evaluated. The initial temperature of both tool and workpiece has been set equal to the room temperature, fixed at $20^{\circ} \mathrm{C}$. The heat exchange coefficient of the two objects with the environment has been applied on their free surface and has been set equal to $20 \mathrm{~W} / \mathrm{m}^{2} \mathrm{~K}$, simulating a convective heat transfer condition, while the one at the tool-chip interface has been imposed equal to $45000 \mathrm{~W} / \mathrm{m}^{2} \mathrm{~K}$, representing heat conduction. The thermal properties of the workpiece have been set in accordance to the DEFORM database, while the ones related to the tool are reported in Table 2. In order to represent the dry cutting conditions, the frictional behavior has been described by the Zorev's hybrid model with a sticking zone extended from the tool edge up to two times the feed rate and a sliding zone in the remaining contact length (Fig. 9). The sticking zone has been characterized by constant frictional stress equal to the shear flow stress $k$, using a shear model with a friction factor $m_{Z}=1$, while for the sliding zone, frictional stresses varying with a percentage of the $35 \%$ of the contact pressure $\sigma_{n}$, defined by a Coulomb model with a friction coefficient of $\mu=0.35$, have been implemented.

To correctly evaluate the wear parameters in terms of temperature, pressure, and velocity at the tool-chip interface, it is mandatory to reach the thermo-mechanical steady-state before the application of the tool wear subroutine. With this intent, and to reduce the computational times, the simulation strategy reported in Fig. 10 has been adopted.

The first stage of this simulation procedure concerns the utilization of the incremental Lagrangian (IL) solver to achieve the mechanical steady-state. The subsequent thermal steady-state is then reached in the second stage, by the exploitation of the arbitrary Lagrangian-Eulerian (ALE) solver. In the third stage, the subroutine for the calculation of the tool wear rate and the worn tool geometry update is called. During this stage, the tool wear rate is calculated for each node in contact with the workpiece, in accordance with the region-dependent tool wear model, considering the interface temperature, the contact pressure, and the sliding velocity. On the basis of the time interval and estimated wear rate, the tool wear is determined, and the tool geometry is updated. The update of the geometry is performed by the movement of the nodes of a quantity equal to the

Fig. 10 Applied simulation strategy

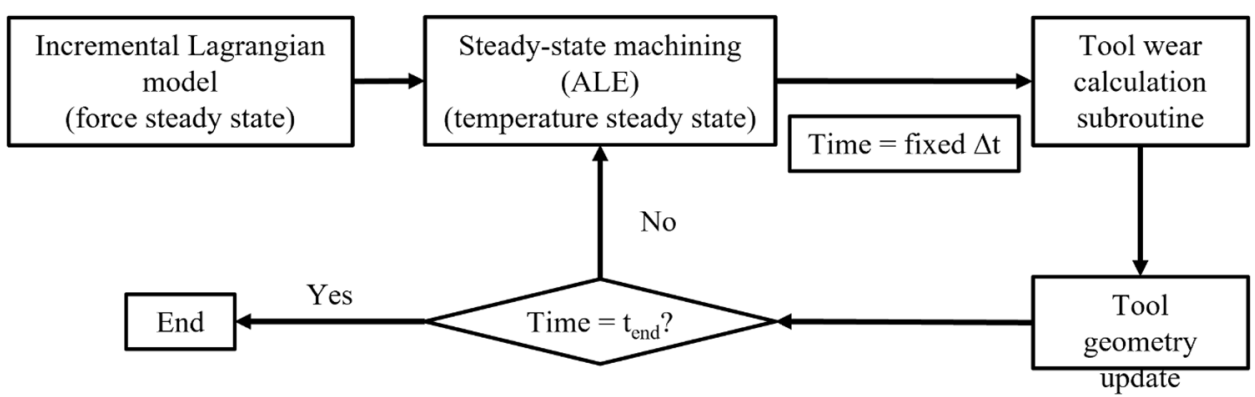




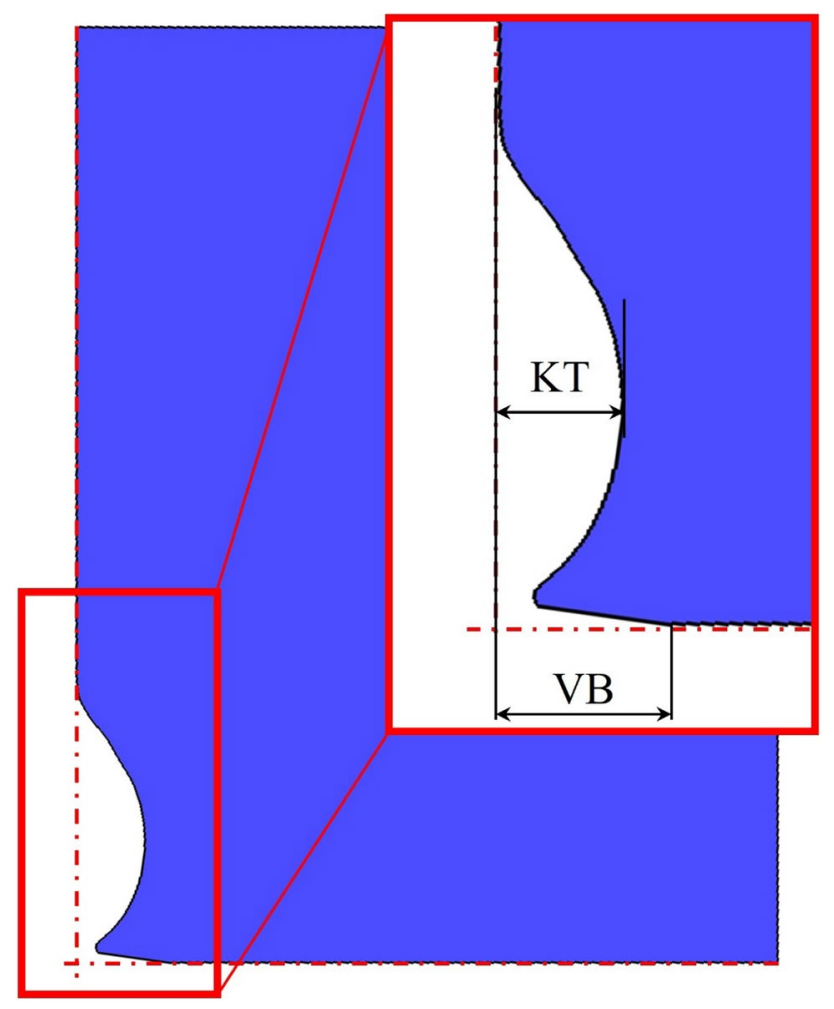

Fig. 11 Simulated crater wear depth and flank wear measurement technique

estimated wear in the opposite direction with respect to the outgoing normal of the elements at which the nodes are connected. Once the updated tool geometry has been assessed, the IL solver is employed again to reach a new thermal and mechanical steady-state considering the worn tool topology. The described technique is iteratively applied until the total machining time is reached. Each iteration coincides to a cutting time according to the time interval of the experimental tests. Figure 11 describes how the measurements of simulated crater wear depth and flank wear have been performed. As indicated by the ISO 3685:1993 standard, the wear parameters must be measured with respect to the outline of a new tool that is represented by the dashed line. In addition, an example of simulated tool wear evolution is visible in Fig. 12.

\section{Results and discussion}

\subsection{Experimental results}

In Fig. 13, the experimental evolutions of flank $(V B)$ and crater $(K T)$ wear as a function of time for each test are visible. From these graphs, it is evident that both flank (Fig. 13a) and crater (Fig. 13b) wear are deeply influenced by the cutting speed: the higher the cutting speed, the higher the tool wear rate. Moreover, the feed rate does not reveal considerable effects of the flank wear rate. In contrast, the influence of feed rate on the crater wear evolution is more prominent. Analyzing more in detail the impact of feed rate on crater wear, by considering the experimental results related to the machining tests, concerning a cutting speed equal to $250 \mathrm{~m} / \mathrm{min}$, it has to be noted that, for the two experiments with lower feed rate $(0.075 \mathrm{~mm} / \mathrm{rev}$ and $0.1 \mathrm{~mm} / \mathrm{rev}$ ), the crater wear rate is similar, while, when considering the highest feed rate $(0.125 \mathrm{~mm} / \mathrm{rev})$, the crater wear rate is higher. The reason of this behavior could be understood considering the geometry of the inserts employed during the experimental tests, in particular the presence of a chamfer with a length of $0.1 \mathrm{~mm}$. Therefore, when applying a feed rate value higher than the chamfer width, the chip displacement is less constrained, taking to a higher sliding velocity and a consequent high temperature generated by friction on the rake face. Hence, an increase of the crater tool wear is expected. From Fig. 13a, it can be observed that the end of all the performed tests has been attained by a catastrophic breakage of the insert before reaching the maximum admitted value of $V B$ of $0.3 \mathrm{~mm}$. The examination of $K T$ evolution indicates that
Fig. 12 Example of tool wear evolution

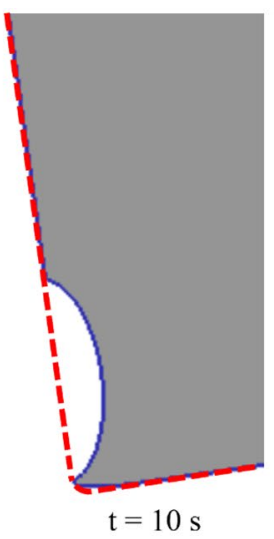

ヘேーーー Unworn tool
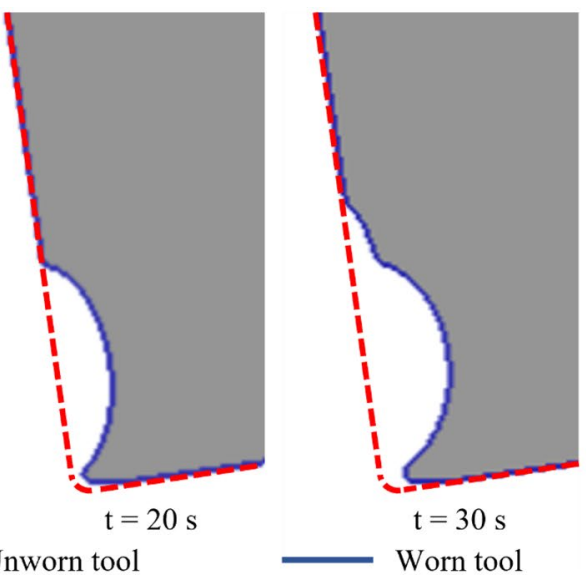
Fig. 13 a, b Evolution of flank wear $(V B)$ and crater wear $(K T)$ throughout the cutting time

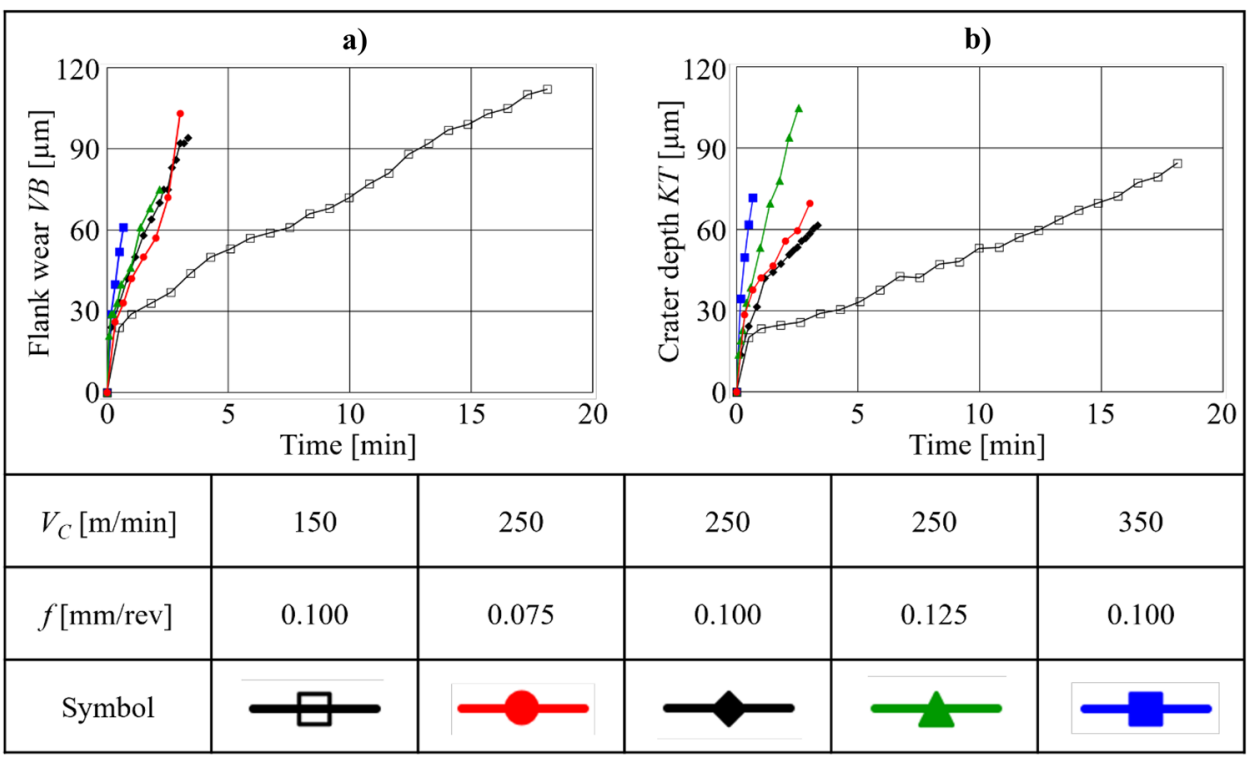

the insert breakage occurs when the crater depth is higher than $60 \mu \mathrm{m}$. The severe crater wear on the PCBN inserts leads to a modification of the tool rake angle from an initial negative value to a positive one (Fig. 14). This geometric alteration reduces the resistant section area of the tool and increases the tensile stresses at which the resistant section is subjected.

This combination, due to the low strength of PCBN tools to tensile stresses, brings to the premature failure of the insert. The previously mentioned behavior has been also verified by a FE simulation of the mechanical stresses generated on the tool during the cutting (Fig. 15).

In Fig. 16, the experimental tool life $(T)$ and the machined volume $(\mathrm{Vol})$ for each tested cutting condition are reported. The calculation of the machined volume has been performed in agreement with Eq. (6) where $\mathrm{Vol}$ is the machined volume $\left[\mathrm{mm}^{3}\right], f$ is the feed rate $[\mathrm{mm} / \mathrm{rev}], d_{C}$ is the depth of cut [mm], $V_{C}$ is the cutting speed $[\mathrm{mm} / \mathrm{min}]$, and $T$ is the tool life [min].

$\mathrm{Vol}=f \cdot d_{C} \cdot V_{C} \cdot T$

The strong influence of cutting speed on the tool life and machined volume, as expected after the previously described tool wear evolution analysis, is evident: the higher the cutting speed, the lower the tool life and the resulting removed volume. As already observed, an increase of the feed rate, once it is above the tool chamfer length, increases the tool wear rate and consequently decreases the tool life. Otherwise, how the machined volume is affected by only the feed rate is not clear and needs further investigations. Once stated the heavy effect of cutting speed on the machined volume, its behavior must be studied also considering the tool life. Therefore, an increase of the feed rate leads to a growing of the removed volume if the tool life is sufficiently high. In the case of a too
Fig. 14 Influence of the effective rake angle value on tool resistance section
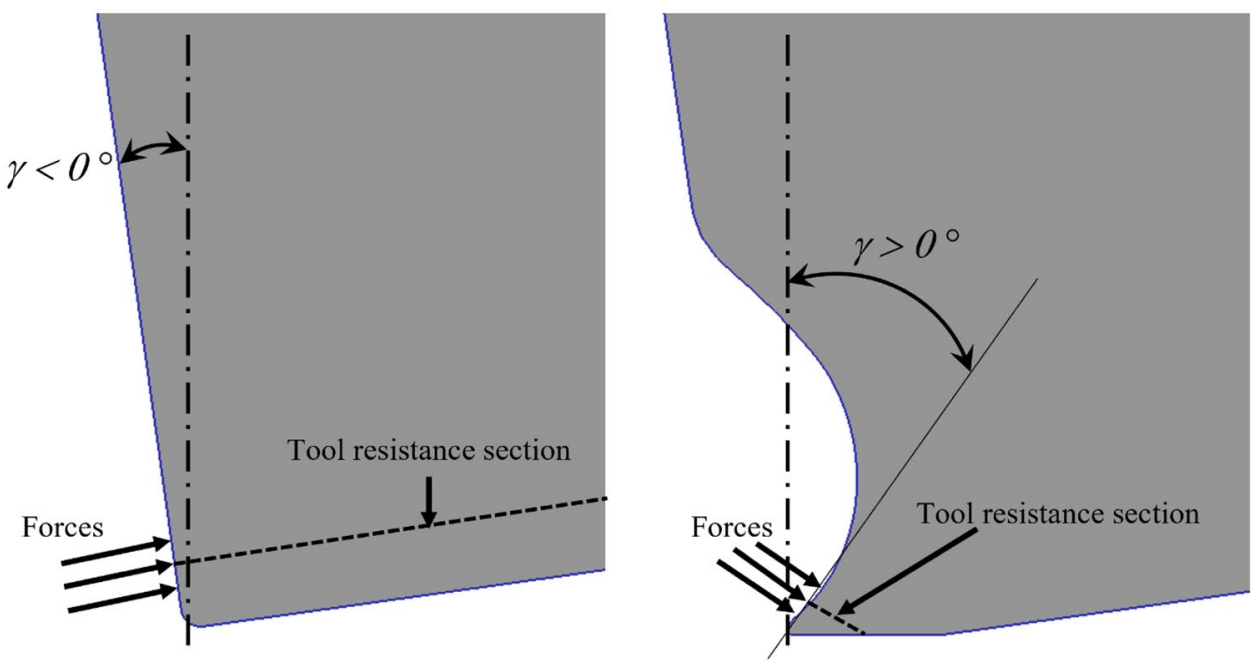


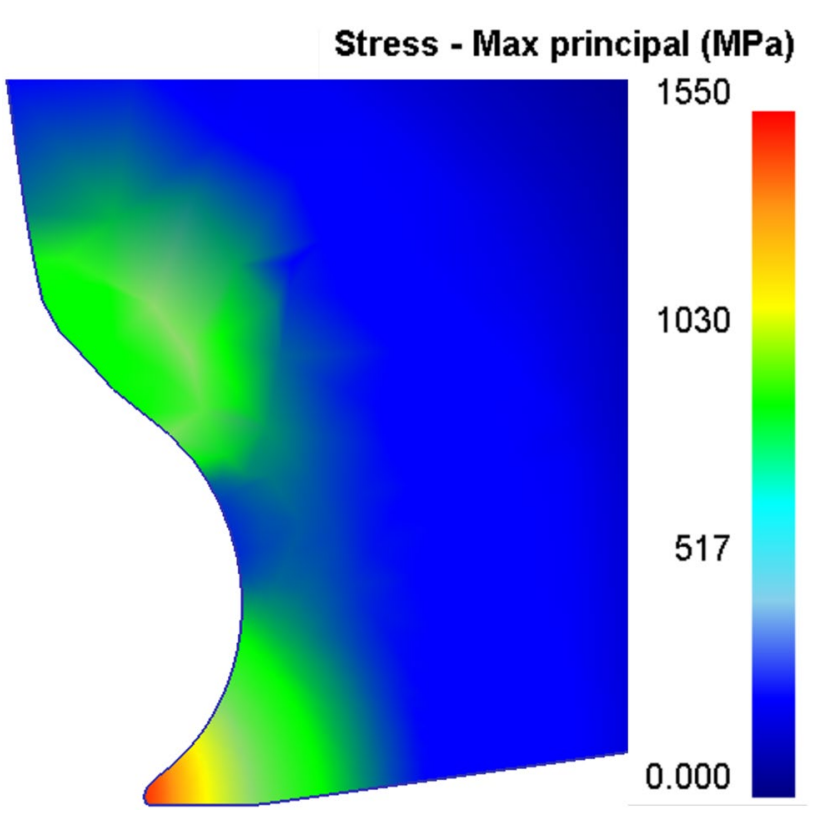

Fig. 15 Maximum principal stresses acting on the worn tool (test T3, cutting time $=180 \mathrm{~s}$ )

much reduced tool life, due to a too high feed rate, as for the test $\mathrm{T} 3$, the machined volume decreases.

\subsection{Simulation results}

The implemented wear model has been validated by the comparison of the simulated tool wear with the experimental one. Figure 17 reports the comparison between experimental and simulated crater wear after 10,20,30, and $40 \mathrm{~s}$ for the test $\mathrm{T} 2$, where the good agreement can be observed indicating the suitability of the model to predict the correct worn tool geometry. Similar results have been achieved for the totality of the tested cases and cutting times.

Figures 18, 19, 20, 21, and 22 report the evolution of simulated tool wear for all the tests performed.

The comparison of the evolution of experimental and simulated crater wear $(K T)$ and flank wear $(V B)$ during the cutting time for all the tests is depicted in the plots of Fig. 23. The good match among the different results is clearly visible. Therefore, the employment of the combined rake-flank tool wear model correctly allows the simulation of the wear behavior of the tool as a function of the cutting parameters, avoiding the need of performing costly and time-consuming experimental tests for the selection of optimized parameters and permitting an accurate tool replacement planning. Another improvement obtained by the implementation of this new tool wear model is the possibility of forecasting the modification of the effective rake angle, due to the growing of crater wear (Fig. 14), during the cutting time. Figure 24 shows the development of simulated effective rake angle during time, normalized with respect to the total tool life of each test. The increase of the crater wear changes the effective rake angle from a negative to a positive value.

It is important to monitor the value of this angle since, due to their high hardness but low toughness, PCBN tools present extremely high resistance to compressive stresses but poor to tensile ones; consequently, the application of a negative rake angle is recommended to enhance resulting compressive stresses on them. Conversely, when the rake
Fig. 16 Removed volume and tool life of the performed experimental tests

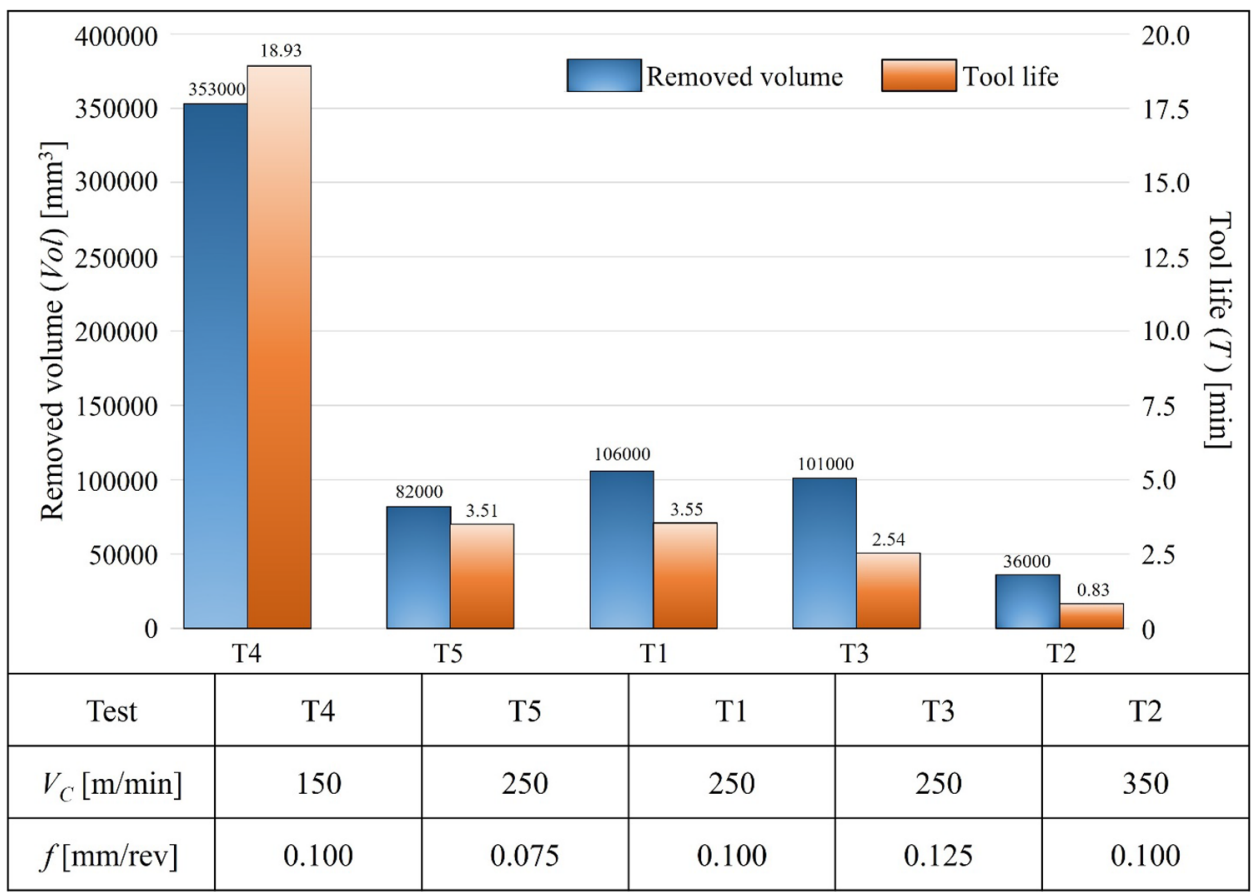


Fig. 17 Comparison between experimental and simulated crater wear along a tool section after 10, 20, 30, and $40 \mathrm{~s}$ (test $\mathrm{T} 2)$
Experimental and Simulated Crater Depth evolution for Test T2
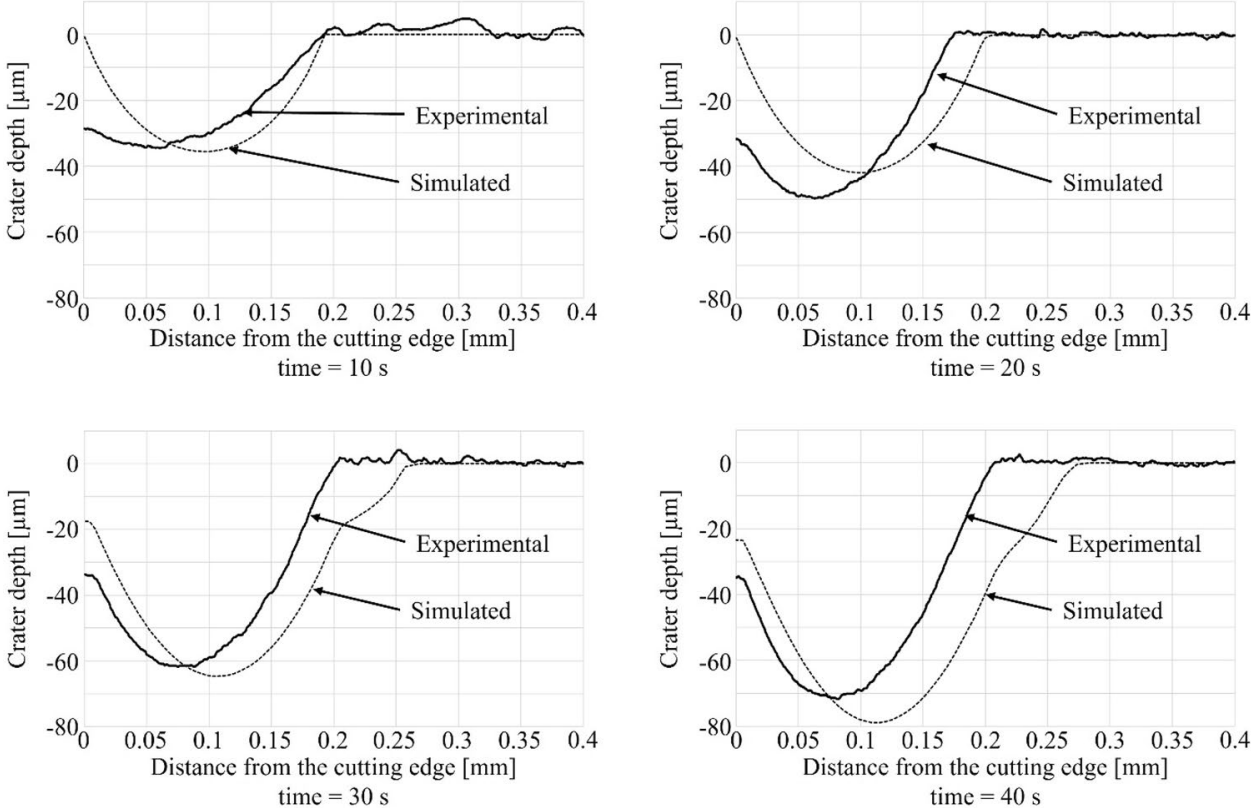

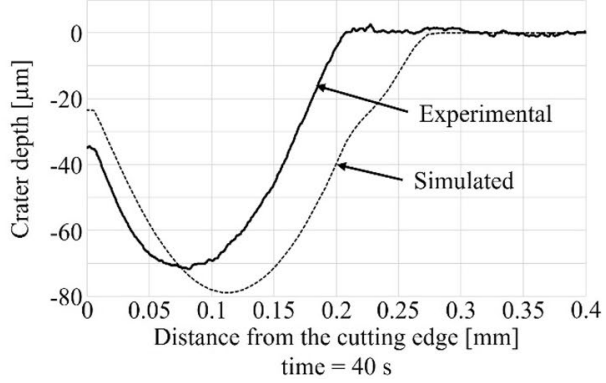

angle is positive, tensile stresses increase. The normalized rake angle evolution of Fig. 24 underlines that the upper limit of the effective rake angle that brings to tool breakage is independent from the process parameters, and this value should range between $20^{\circ}$ and $30^{\circ}$ for all the tests.

The machining simulation of the tool worn topology, and the resulting effective rake angle, allows to forecast, by the estimation of the resultant cutting forces and stresses, the tool catastrophic breakage. Figure 25 shows the evolution during time of the maximum principal stresses on the tool for the different tests. For simplicity, the cutting time on the ordinate axis has been normalized with respect to the total tool life for each test.

It is clearly visible that when the cutting time increases, the maximum principal stress on the tool increases too. From the observation of the plot of Fig. 25 in correspondence with the $100 \%$ of the tool life, it can be asserted that tool breakage occurs when high values of the maximum tensile stresses are reached, particularly with values above $2100 \mathrm{MPa}$. This is due to the high brittleness, and the related low capacity to support high tensile stresses, of PCBN tools. As already highlighted, an increase of tool wear leads to two important phenomena: the reduction of the tool strength, due to the decrease of its resistant cross-section, and the shift of the effective rake angle from a negative value to an increasingly positive one. The high positive value of the rake angle induces tensile stresses on the tool. In addition, by a combined analysis of the plots in Figs. 24 and 25, it can be affirmed that growing of the rake angle raises the value of tensile stresses. The simultaneous presence of tensile stress augmentation and tool strength reduction, also considering the poor resistance of tool material at tensile stresses, lead to
Fig. 18 Simulated tool wear evolution for test $\mathrm{T} 1$
Tool wear evolution for test $\mathrm{T} 1\left(V_{C}=250 \mathrm{~m} / \mathrm{min} ; f=0.100 \mathrm{~mm} / \mathrm{rev}\right)$

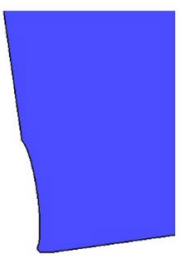

$\mathrm{t}=10 \mathrm{~s}$

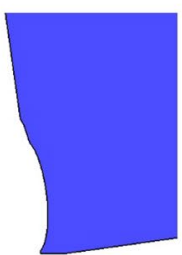

$\mathrm{t}=30 \mathrm{~s}$

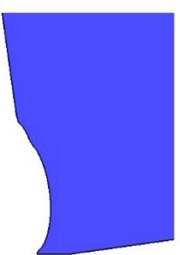

$\mathrm{t}=50 \mathrm{~s}$

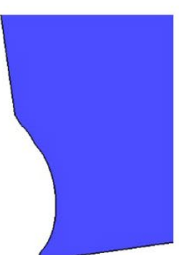

$\mathrm{t}=70 \mathrm{~s}$

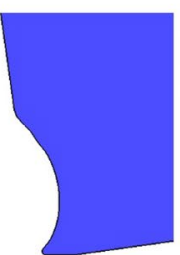

$\mathrm{t}=90 \mathrm{~s}$

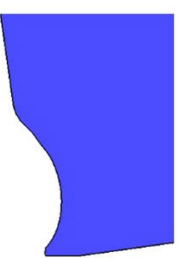

$\mathrm{t}=110 \mathrm{~s}$

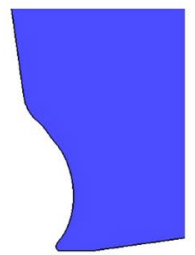

$\mathrm{t}=130 \mathrm{~s}$

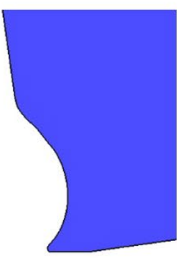

$\mathrm{t}=150 \mathrm{~s}$

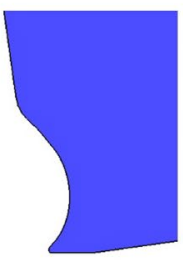

$\mathrm{t}=170 \mathrm{~s}$

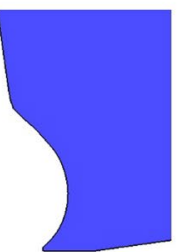

$t=190 s$

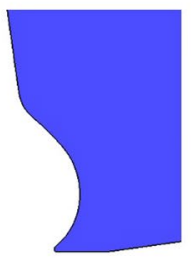

$\mathrm{t}=200 \mathrm{~s}$ 
Fig. 19 Simulated tool wear evolution for test $\mathrm{T} 2$

Fig. 20 Simulated tool wear evolution for test T3

Fig. 21 Simulated tool wear evolution for test T4
Tool wear evolution for test $\mathrm{T} 2\left(V_{C}=350 \mathrm{~m} / \mathrm{min} ; f=0.100 \mathrm{~mm} / \mathrm{rev}\right)$

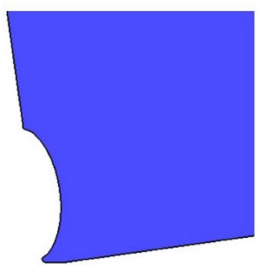

$\mathrm{t}=10 \mathrm{~s}$

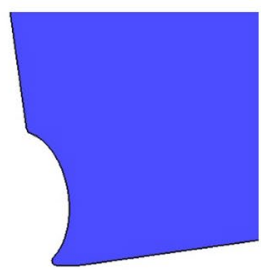

$\mathrm{t}=20 \mathrm{~s}$

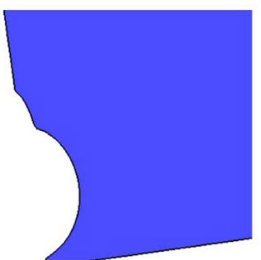

$\mathrm{t}=30 \mathrm{~s}$

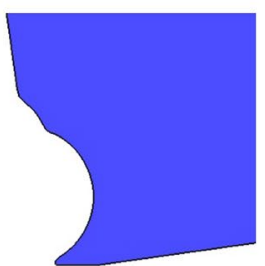

$t=40 s$

Tool wear evolution for test T3 $\left(V_{C}=250 \mathrm{~m} / \mathrm{min} ; f=0.125 \mathrm{~mm} / \mathrm{rev}\right)$

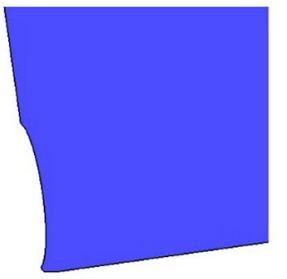

$$
\mathrm{t}=10 \mathrm{~s}
$$

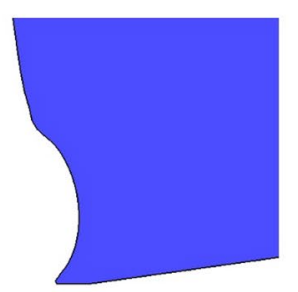

$\mathrm{t}=80 \mathrm{~s}$

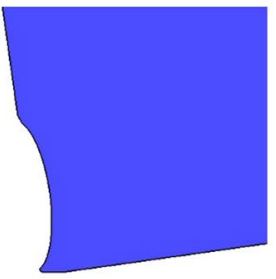

$\mathrm{t}=20 \mathrm{~s}$

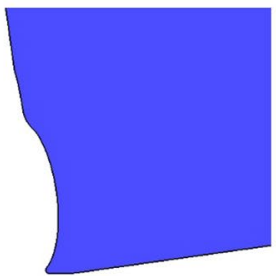

$\mathrm{t}=30 \mathrm{~s}$

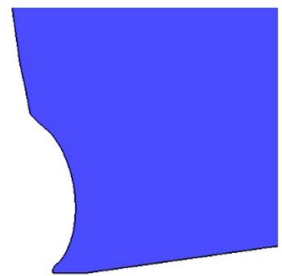

$t=60 s$

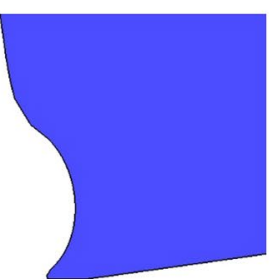

$\mathrm{t}=105 \mathrm{~s}$

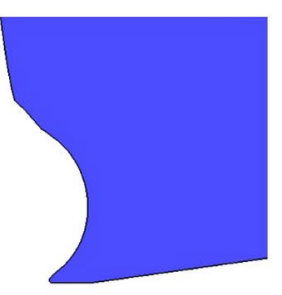

$t=130 s$

Tool wear evolution for test T4 $\left(V_{C}=150 \mathrm{~m} / \mathrm{min} ; f=0.100 \mathrm{~mm} / \mathrm{rev}\right)$

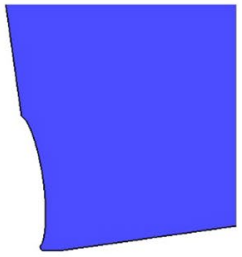

$\mathrm{t}=30 \mathrm{~s}$

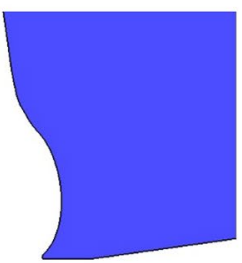

$\mathrm{t}=500 \mathrm{~s}$

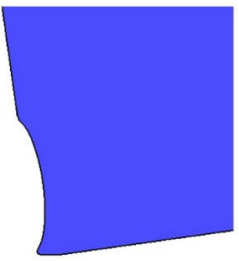

$\mathrm{t}=110 \mathrm{~s}$

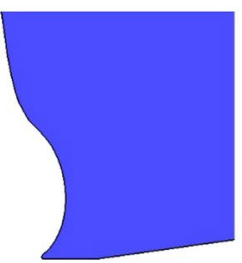

$t=800 s$

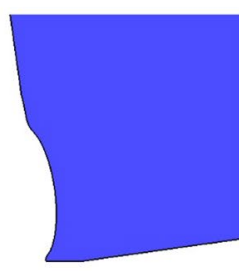

$\mathrm{t}=210 \mathrm{~s}$

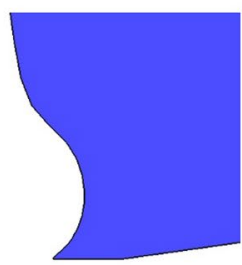

$\mathrm{t}=1000 \mathrm{~s}$

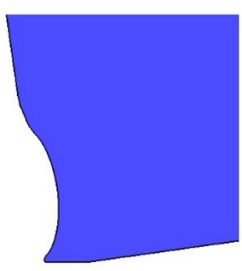

$\mathrm{t}=350 \mathrm{~s}$

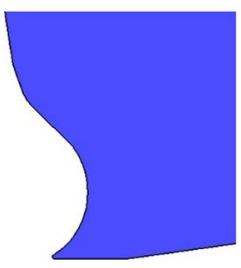

$t=1100 \mathrm{~s}$ 
Fig. 22 Simulated tool wear evolution for test T5

Tool wear evolution for test $\mathrm{T} 5\left(V_{C}=250 \mathrm{~m} / \mathrm{min} ; f=0.075 \mathrm{~mm} / \mathrm{rev}\right)$

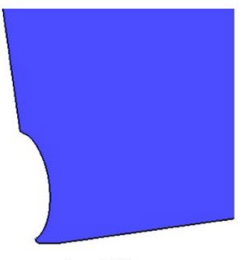

$\mathrm{t}=20 \mathrm{~s}$

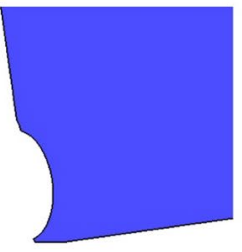

$t=40 s$

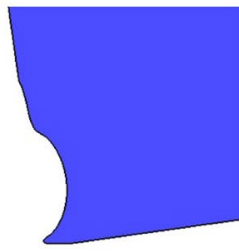

$\mathrm{t}=60 \mathrm{~s}$

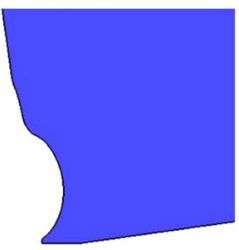

$\mathrm{t}=90 \mathrm{~s}$

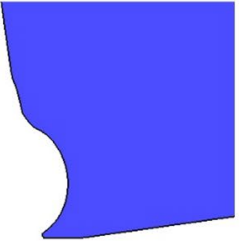

$\mathrm{t}=120 \mathrm{~s}$

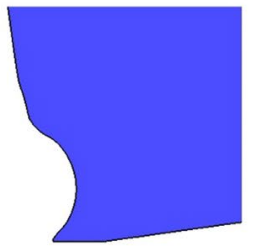

$\mathrm{t}=150 \mathrm{~s}$

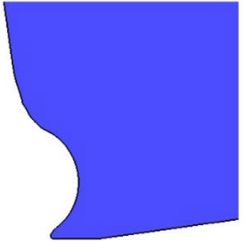

$\mathrm{t}=180 \mathrm{~s}$
Fig. 23 Comparison between experimental and simulated $K T$ and $V B$ values
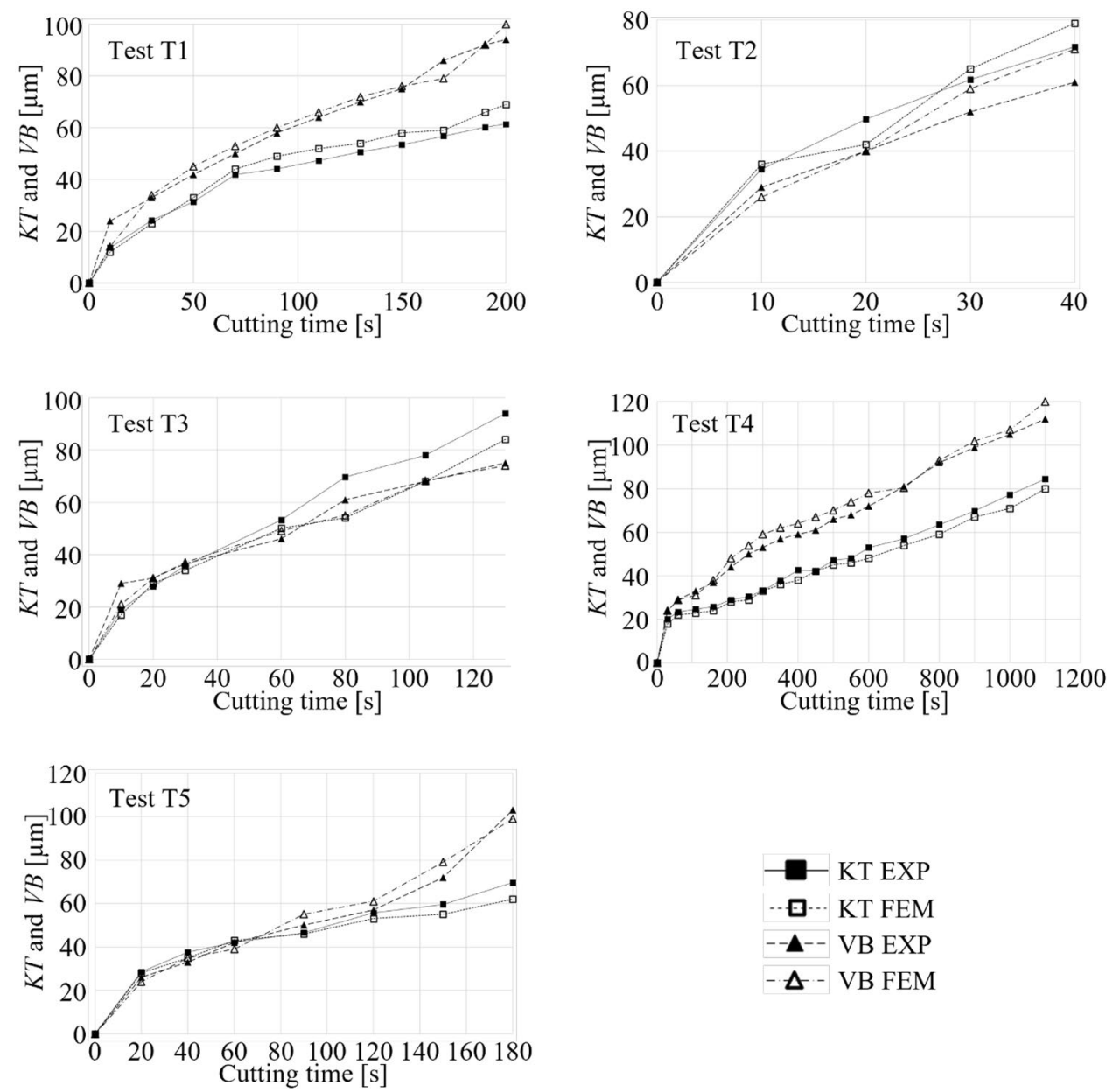

- KT EXP

-... KT FEM

$--\mathbf{A}^{--}$VB EXP

$\Delta$ VB FEM 
Fig. 24 Normalized effective angle evolution for all the performed tests

Fig. 25 Simulated maximum principal stress on tool
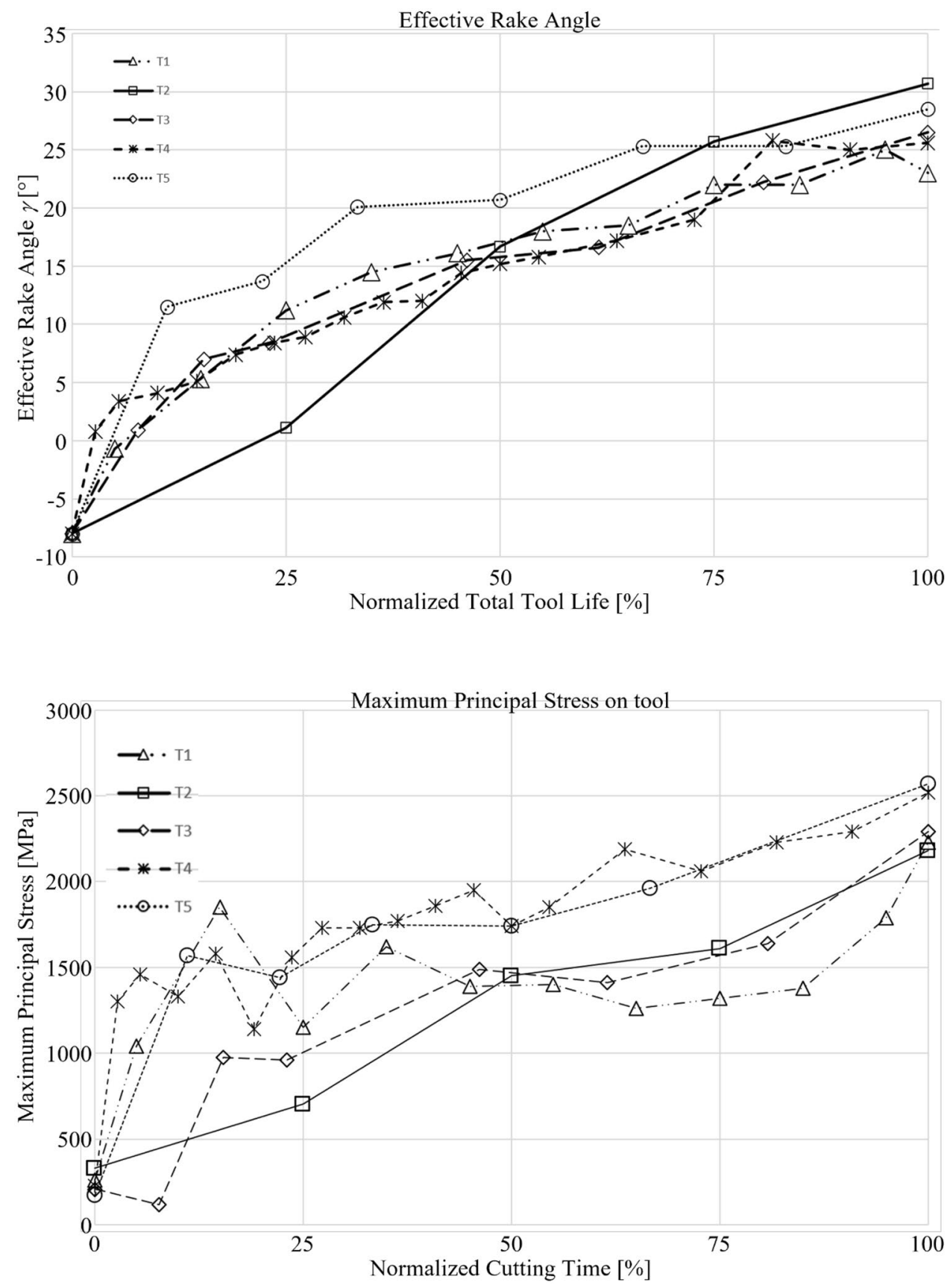

the catastrophic breakage of the tool. Therefore, coupling the simulated worn geometry of the tool and its stress analysis during the machining operation, it is possible to evaluate the stresses at which the tool is subjected and estimate if a sudden rupture would occur.

\section{Conclusions}

In the present paper, the results achieved from a study on tool wear simulation of PCBN inserts when cutting AISI 52100 hardened steel, aimed to improve the quality and the reliability of FEM analysis of machining operations, have been presented. Simulations replicating experimental tests have been performed. In order to correctly set up cutting simulations, a preventive analysis of the constitutive law of workpiece material has been exploited by the comparison of experimental and simulated cutting forces, leading to the implementation of a modified hyperbolic tangent Johnson-Cook's flow stress model also able to describe chip segmentation. Moreover, a coupled abrasive-diffusive crater wear model and an abrasive flank wear model able to update the geometry of the worn tool during machining simulation, have been implemented into a FEM engine by means of a 
suitable subroutine. Experimental and simulated wear parameters have been compared in terms of crater depth and flank wear width. This comparison demonstrated the capability of the FEM model to closely reproduce the tool wear throughout the cutting time. Some differences have been detected for the lowest cutting speed test, where the FEM model overestimated the crater depth in the firsts 5 min of cutting. The experimental behavior of the crater depth is not clear and needs to be deeply examined by further investigations.

The validated FEM model has been also employed to analyze the effect of tool wear on the effective rake angle and related maximum principal stress values on the insert. This underlined how the increase of crater depth leads to a transformation of the rake angle from a negative value to a positive one, reducing the resistance section and enhancing tensile stresses of the tool. The combination of these two aspects, correlated with the high brittleness of PCBN material, has been individuated as the mechanism of failure of the tool, bringing to premature breakage before reaching the limit value of flank wear.

Hence, the proposed FEM strategy can be applied to optimize the process parameters by continuously monitoring crater and flank wear evolution, preventing catastrophic rupture and allowing a correct replacement of the tool.

Author contribution All authors contributed to the study conception and design. Material preparation, data collection, and analysis were performed by AA and CC. The first draft of the manuscript was written by $\mathrm{CC}$ and all authors commented on previous versions of the manuscript. All authors read and approved the final manuscript.

Availability of data and material The authors declare that there are no restrictions in the availability of data and material.

Code availability The proposed subroutine has been implemented in commercial code DEFORM-2D.

\section{Declarations}

Ethics approval Not applicable.

Consent to participate Not applicable.

Consent for publication Not applicable.

Competing interests The authors declare no competing interests.

Open Access This article is licensed under a Creative Commons Attribution 4.0 International License, which permits use, sharing, adaptation, distribution and reproduction in any medium or format, as long as you give appropriate credit to the original author(s) and the source, provide a link to the Creative Commons licence, and indicate if changes were made. The images or other third party material in this article are included in the article's Creative Commons licence, unless indicated otherwise in a credit line to the material. If material is not included in the article's Creative Commons licence and your intended use is not permitted by statutory regulation or exceeds the permitted use, you will need to obtain permission directly from the copyright holder. To view a copy of this licence, visit http://creativecommons.org/licenses/by/4.0/.

\section{References}

1. Panda A, Sahoo AK, Kumar R, Das RK (2020) A review on machinability aspects for AISI 52100 bearing steel. Mater Today Proc 23:617-621. https://doi.org/10.1016/j.matpr.2019.05.422

2. Cappellini C, Attanasio A, Rotella G, Umbrello D (2010) Formation of white and dark layers in hard cutting: influence of tool wear. Int J Mater Form 3:455-458. https://doi.org/10.1007/ s12289-010-0805-1

3. Bartarya G, Choudhury SK (2012) State of the art in hard turning. Int J Mach Tools Manuf 53:1-14. https://doi.org/10.1016/j. ijmachtools.2011.08.019

4. Uhlmann E, Mahnken R, Ivanov IM, Cheng C (2015) A novel finite element approach to modeling hard turning in due consideration of the viscoplastic asymmetry effect. Procedia CIRP 31:471-476. https://doi.org/10.1016/j.procir.2015.03.093

5. Law M, Karthik R, Sharma S, Ramkumar J (2020) Finish turning of hardened bearing steel using textured PcBN tools. J Manuf Process 60:144-161. https://doi.org/10.1016/j.jmapro. 2020.10.051

6. Sales WF, Schoop J, da Silva LRR, Machado AR, Jawahir IS (2020) A review of surface integrity in machining of hardened steels. J Manuf Process 58:136-162. https://doi.org/10.1016/j. jmapro.2020.07.040

7. Siraj S, Dharmadhikari HM, Gore N (2018) Modeling of roughness value from tribological parameters in hard turning of AISI 52100 steel. Procedia Manuf 20:344-349. https://doi.org/10. 1016/j.promfg.2018.02.050

8. Sankar BR, Rao PU (2017) Analysis of forces during hard turning of AISI 52100 steel using Taguchi method. Mater Today Proc 4:2114-2118. https://doi.org/10.1016/j.matpr.2017.02.057

9. Pradeep AV, Raju DL, Ramakrishna S (2019) Cutting force analysis in hard turning of AISI 52100 steel using multi-layer coated carbide inserts - RSM approach. Mater Today Proc. https://doi. org/10.1016/j.matpr.2019.07.369

10. Zhang W, Zhuang K (2020) Effect of cutting edge microgeometry on surface roughness and white layer in turning AISI 52100 steel. Procedia CIRP 87:53-58. https://doi.org/10.1016/j.procir. 2020.02.079

11. Çetindağ HA, Çiçek A, Uçak N (2020) The effects of CryoMQL conditions on tool wear and surface integrity in hard turning of AISI 52100 bearing steel. J Manuf Process 56:463-473. https:// doi.org/10.1016/j.jmapro.2020.05.015

12. Baizeau T, Campocasso S, Fromentin G, Rossi F, Poulachon G (2015) Effect of rake angle on strain field during orthogonal cutting of hardened steel with c-BN tools. Procedia CIRP 31:166-171. https://doi.org/10.1016/j.procir.2015.03.089

13. Magalhães FC, Ventura CEH, Abrão AM, Denkena B (2020) Experimental and numerical analysis of hard turning with multi-chamfered cutting edges. J Manuf Process 49:126-134. https://doi.org/10.1016/j.jmapro.2019.11.025

14. Denkena B, Bergmann B, Grove T, Pape O (2017) Increasing productivity in turning of hard-to-cut materials by means of modified flank faces. Procedia Manuf 14:97-104. https://doi. org/10.1016/j.promfg.2017.11.011

15. Huang Y, Dawson TG (2005) Tool crater wear depth modeling in CBN hard turning. Wear 258:1455-1461. https://doi.org/10. 1016/j.wear.2004.08.010 
16. Clavier F, Valiorgue F, Courbon C, Rech J, Van Robaeys A, Masciantonio U, Brosse A, Dorlin T (2021) Numerical analysis of the tribological and geometrical impacts of tool wear on the thermomechanical loadings induced by $15-5 \mathrm{PH}$ steel turning. Procedia CIRP 102:411-416. https://doi.org/10.1016/j.procir. 2021.09.070

17. Clavier F, Valiorgue F, Courbon C, Dumas M, Rech J, Van Robaeys A, Lefebvre F, Brosse A, Karaouni H (2020) Impact of cutting tool wear on residual stresses induced during turning of a 15-5 PH stainless steel. Procedia CIRP 87:107-112. https://doi. org/10.1016/j.procir.2020.02.074

18. Yallese MA, Chaoui K, Zeghib N, Boulanova L, Rigal JF (2009) Hard machining of hardened bearing steel using cubic boron nitride tool. J Mater Process Technol 209:1092-1104. https://doi. org/10.1016/j.jmatprotec.2008.03.014

19. Attanasio A, Umbrello D, Cappellini C, Rotella G, M'Saoubi R (2012) Tool wear effects on white and dark layer formation in hard turning of AISI 52100 steel. Wear 286-287:98-107. https://doi. org/10.1016/j.wear.2011.07.001

20. Zemzemi F, Khochtali H, Salem WB, Alzahrani B, Bouazizi ML (2021) Analytical multi-physics model of microstructure changes in hard turning of AISI 52100 steel: prediction of thicknesses of white and dark layers. Int J Adv Manuf Technol 112:2755-2771. https://doi.org/10.1007/s00170-020-06521-1

21. Poulachon G, Moisan A, Jawahir IS (2001) Tool-wear mechanisms in hard turning with polycrystalline cubic boron nitride tools. Wear 250:576-586. https://doi.org/10.1016/S0043-1648(01) 00609-3

22. Huang Y, Chou YK, Liang SY (2007) CBN tool wear in hard turning: a survey on research progresses. Int J Adv Manuf Technol 35:443-453. https://doi.org/10.1007/s00170-006-0737-6

23. Gordon S, Phelan P, Lahiff C (2019) The effect of high speed machining on the crater wear behaviour of PCBN tools in hard turning. Procedia Manuf 38:1833-1848. https://doi.org/10.1016/j. promfg.2020.01.076

24. Singh D, Rao PV (2010) Flank wear prediction of ceramic tools in hard turning. Int J Adv Manuf Technol 50:479-493. https://doi. org/10.1007/s00170-010-2550-5

25. Chinchanikar S, Choudhury SK (2015) Predictive modeling for flank wear progression of coated carbide tool in turning hardened steel under practical machining conditions. Int J Adv Manuf Technol 76:1185-1201. https://doi.org/10.1007/s00170-014-6285-6

26. Öztürk S, Altan E (2012) A slip-line approach to the machining with round-edge tool. Int J Adv Manuf Technol 65:513-522. https://doi.org/10.1007/s00170-012-3941-6

27. Öztürk S (2012) Slip-line modeling of machining and determine the influence of rake angle on the cutting force. Trans Can Soc Mech Eng 36:23-35. https://doi.org/10.1139/tcsme-2012-0002

28. Öztürk S (2016) Application of the Taguchi method for surface roughness predictions in the turning process. Mater Test 58(9):782-787. https://doi.org/10.3139/120.110917

29. Kahraman MF, Öztürk S (2019) Experimental study of newly structural design grinding wheel considering response surface optimization and Monte Carlo simulation. Measurement 147:106825. https://doi.org/10.1016/j.measurement.2019.07.053

30. Paturi UMR, Cheruku S, Pasunuri VPK, Salike S (2020) Modeling of tool wear in machining of AISI 52100 steel using artificial neural networks. Mater Today Proc 38:2358-2365. https://doi.org/ 10.1016/j.matpr.2020.06.581

31. Li B (2012) A review of tool wear estimation using theoretical analysis and numerical simulation technologies. Int J Refract Met Hard Mater 35:143-151. https://doi.org/10.1016/j.ijrmhm.2012. 05.006

32. Umbrello D, Filice L, Micari F, Matsumura T, Shirakashi T (2008) Prediction of tool wear progress in machining of carbon steel using different tool wear mechanisms. Int J Mater Form 1:571-574. https://doi.org/10.1007/s12289-008-0320-9

33. Attanasio A, Ceretti E, Fiorentino A, Cappellini C, Giardini C (2010) Investigation and FEM-based simulation of tool wear in turning operations with uncoated carbide tools. Wear 269:344350. https://doi.org/10.1016/j.wear.2010.04.013

34. Thepsonthi T, Özel T (2015) 3-D finite element process simulation of micro-end milling Ti-6Al-4V titanium alloy: experimental validations on chip flow and tool wear. J Mater Process Technol 221:128-145. https://doi.org/10.1016/j.jmatprotec.2015.02.019

35. Yadav RK, Abhishek K, Mahapatra SS (2015) A simulation approach for estimating flank wear and material removal rate in turning of Inconel 718. Simul Model Pract Theory 52:1-14. https://doi.org/10.1016/j.simpat.2014.12.004

36. Ramìrez FP, Soldani X, Loya J, Miguélez H (2017) A new approach for time-space wear modeling applied to machining tool wear. Wear 390-391:125-134. https://doi.org/10.1016/j.wear. 2017.07.015

37. Melkote SN, Grzesik W, Outeiro J, Rech J, Schulze V, Attia H, Arrazola PJ, M'Saoubi R, Saldana C (2017) Advances in material and friction data for modeling of metal machining. CIRP Ann Manuf Technol 66:731-754. https://doi.org/10.1016/j.cirp.2017. 05.002

38. Huang Y, Liang SY (2003) Cutting forces modeling considering the effect of tool thermal property-application to CBN hard turning. Int J Mach Tools Manuf 43:307-315. https://doi.org/10.1016/ S0890-6955(02)00185-2

39. Poulachon G, Moisan AL, Jawahir IS (2007) Evaluation of chip morphology in hard turning using constitutive models and material property data. J Manuf Sci Eng 129:41-47. https://doi.org/10. $1115 / 1.2335850$

40. Umbrello D, Hua J, Shivpuri R (2004) Hardness based flow stress for numerical modeling of hard machining AISI 52100 bearing steel. Mater Sci Eng A 347:90-100. https://doi.org/10.1016/j. msea.2004.01.012

41. Kountanya R, Al-Zkeri I, Altan T (2009) Effect of tool edge geometry and cutting conditions on experimental and simulated chip morphology in orthogonal hard turning of $100 \mathrm{Cr} 6$ steel. J Mater Process Technol 209:5068-5076. https://doi.org/10.1016/j.jmatprotec.2009. 02.011

42. Zhang F, Duan C, Wei S, Kang J (2019) Effects of cutting conditions on the microstructure and residual stress of white and dark layers in cutting hardened steel. J Mater Process Technol 266:599-611. https://doi.org/10.1016/j.jmatprotec.2018.11.038

43. Ceretti E, Lucchi M, Altan T (1999) FEM simulation of orthogonal cutting: serrated chip formation. J Mater Process Technol 95:17-26. https://doi.org/10.1016/S0924-0136(99)00261-7

44. Arrazola PJ, Kortabarria A, Madariaga A, Esnaola JA, Fernandez E, Cappellini C, Ulutan D, Özel T (2014) On the machining induced residual stresses in IN718 nickel-based alloy: experiments and predictions with finite element simulation. Simul Model Pract Theory 41:87-103. https://doi.org/10.1016/j.simpat.2013.11.009

45. Umbrello D (2011) Influence of material microstructure changes on surface integrity in hard machining of AISI 52100 steel. Int J Adv Manuf Technol 54:887-898. https://doi.org/10.1007/ s00170-010-3003-x

46. Zorev NN (1966) Metal cutting mechanics. Pergamon Press, Oxford

Publisher's Note Springer Nature remains neutral with regard to jurisdictional claims in published maps and institutional affiliations. 